\title{
Selective Secondary Education and School Participation in Sub- Saharan Africa: Evidence from Malawi
}

\author{
By JACOBUS DE HOOP ${ }^{1}$
}

August 6, 2010

Large scale tracking policies, allowing academically apt pupils to enter a select group of secondary schools, can be found in many Sub-Saharan countries. However, evidence on the impact of these policies on school outcomes, especially school participation, is limited. This paper fills this gap by providing regression discontinuity evidence on the impact of Malawi's tracking program. The analysis is based on unique institutional data covering an entire cohort of pupils. Estimates show that Malawi's tracking program raises school participation of top students without a reduction in pupil learning. These findings have implications for education policy in Sub-Sabaran Africa.

(JEL I20, I21, O15)

\footnotetext{
1 Tinbergen Institute and VU University Amsterdam, De Boelelaan 1105, 1081 HV Amsterdam, the Netherlands. (email: hoop@tinbergen.nl). I thank Sarah Baird, Pierre-André Chiappori, Ephraim Chirwa, Chris Elbers, Jan Willem Gunning, Craig McIntosh, Berk Özler, participants at the CSAE 2010 conference in Oxford, especially Isaac Mbiti, as well as participants in seminars at the Tinbergen Institute, the University of Amsterdam, and the VU University Amsterdam for valuable comments and for support in collecting the data for this study. I also thank the officials at Malawi's Ministry of Education and the Malawi National Examinations Board who kindly assisted by providing the necessary data and information for this research.
} 
The education sectors of most Sub-Saharan countries face chronic shortages in physical and human resources. Rather than distributing the limited resources available for secondary education uniformly across schools, many governments allocate a relatively large share of the available resources to a select number of secondary schools. Admission to these schools is typically meritbased and determined on the basis of an exam. Examples of such tracking policies can be found in, for instance, Botswana, Chad, Ghana, Kenya, Malawi, Nigeria, Senegal, and Uganda. ${ }^{2}$ Presumably, these policies are in place to ensure that annually at least a minimum number of relatively welleducated individuals enter tertiary education or the labor force. Although they are common, little is known about the effectiveness of these policies. This paper attempts to fill this gap by investigating the impact of the tracking policy employed in Malawi's secondary schools on school outcomes.

Malawi's public secondary schools can be divided into 2 main categories: conventional schools and community day schools. Conventional schools are universally favored by parents and pupils. Disparities between conventional schools and community day schools in terms of physical and human resources are large. Together these two categories of public secondary schools can accommodate approximately $40 \%$ of the 100,000 pupils who annually successfully complete the primary school exam.

Pupils are selected into a fixed number of places available in these 2 categories of secondary schools based on their performance on the Primary School Leaving Certificate Examination (PSLCE). The top performers on the PSLCE are selected into conventional schools. Second tier performers on the PSLCE are selected into community day schools. Third tier performers are not selected into public secondary schools. They either drop out or enter private secondary schools, which are generally poorly equipped and scantly staffed institutions even in comparison to community day schools. By selecting pupils into specific community day schools and conventional

${ }^{2}$ As can be inferred from http://education.stateuniversity.com 
schools, the Ministry of Education not only severely restricts school choice between, but also within these two school types.

Selection into a conventional school is a multidimensional treatment, as pupils who are selected into conventional schools enter better endowed schools and are surrounded by a select peer group. This paper exploits the restricted school choice between community day schools and conventional schools, which can be interpreted as an application of the regression discontinuity design, to identify the impact of this multidimensional treatment on pupil learning and pupil retention. ${ }^{3}$ The main idea being that pupils with a PSLCE score just below the cutoff for selection into a conventional school serve as a valid counterfactual for pupils with a PSLCE just above the cutoff as they are in principle comparable in terms of unobserved characteristics.

The analysis is based on unique data that cover an entire cohort of students who took the PSLCE at the end of 2004 and were selected to enter a community day school or conventional school at the start of 2005. I linked the 2004 PSLCE scores of these pupils to their performance on the 2006 junior certificate examination (JCE), an exam that all students must take at the end of their second year in secondary school. Looking at an entire cohort of pupils has the advantage that the relevance of the analysis is not reduced by external validity concerns.

The regression discontinuity estimates show that the tracking procedure effectively raises school outcomes of pupils selected into conventional secondary schools. First, pupil retention rates (as measured by the fraction of pupils participating in the JCE) are roughly $50 \%$ higher in conventional secondary schools. Second, a bounds analysis shows that pupil learning in conventional schools (as measured by performance on the JCE) is at least equal to, but possibly markedly higher than pupil learning in community day schools.

\footnotetext{
3 This paper refers to the ability of schools to keep pupils in school and to make sure that they progress through the system as "retention". Retention never refers to the act of making a pupil repeat a grade.
} 
These outcomes provide the first evidence on the impact of large scale tracking across schools in Sub-Saharan Africa on pupil retention. This evidence can serve as a valuable input for policy makers in Sub-Saharan Africa when they evaluate their tracking policies. The evidence is also highly relevant for parents and pupils, as it tells them why it matters for pupils to get into a good secondary school.

In addition, the outcomes serve as a more general indication that the school environment (a combination of school characteristics and peers) matters for pupil retention in Sub-Saharan Africa. Prior evidence for this intuitively appealing proposition is limited, because self-selection issues tend to hinder clean identification (Paul Glewwe, 2002; Paul Glewwe and Michael Kremer, 2006). Two studies on South-Africa and India, respectively based on a natural experiment and a field experiment, suggest that the teacher to pupil ratio, an important measure of school quality, may affect school participation (Abhijit V. Banerjee, Suraj Jacob, and Michael Kremer, 2000; Anne Case and Angus Deaton, 1999). Randomized experiments in Kenya, on the other hand, show no detectable relationship between inputs like textbooks and school participation (e.g. Paul Glewwe, Michael Kremer, and Sylvie Moulin, 2000).

The evidence for the role played by the school environment in pupil learning is more abundant. Esther Duflo, Pascaline Dupas, and Michael Kremer (2008), for instance, show that a tracking experiment within schools in Kenya positively affected learning of pupils across all levels of the ability distribution. Similarly, Abhijit V. Banerjee et al. (2007) found that remedial education and computer assisted learning had a positive impact on pupil learning, because pupils could work at their own ability level. The literature on peer effects substantiates the finding that peers matter for pupil learning (e.g. Caroline Hoxby, 2000; Bruce Sacerdote, 2001; David J. Zimmerman 2003; Weili Ding and Steven F. Lehrer 2007; David S. Lyle 2007; Victor Lavy, Daniele Paserman, and Analia Schlosser, 2008). And teachers have also been shown to play an important role in pupil learning (e.g. 
Joshua D. Angrist and Victor Lavy, 1999; Steven G. Rivkin, Eric A. Hanushek, and John F. Kain, 2005). The results on pupil learning presented in this paper, although estimated with wide bounds, are in accordance with this body of evidence.

The remainder of this paper proceeds as follows. Section I provides some background on the education sector in Malawi. Section II discusses the methodology. Section III describes the data. Section IV presents the main results. Section V discusses the validity of the methodology and the robustness of the results. Section VI concludes.

\section{Background}

\section{A. Basic Facts}

Malawi is a relatively small landlocked country in Sub-Saharan Africa. In 2005, the year in which the cohort under consideration entered secondary school, it had almost 14 million inhabitants. Due to high birth and mortality rates a high proportion of Malawi's population is of primary or secondary school age. According to the Ministry of Education (2005) there were approximately 2.5 million children of primary school age and 1 million children of secondary school age in 2005.

Basic education in Malawi consists of 8 years of primary education (standard 1 through 8 ) and 4 years of secondary education (Form 1 through 4). All primary and all secondary schools offer the same curriculum, the contents of which are determined by the Ministry of Education.

\section{B. Primary Education in Malawi}

For most Malawians access to formal primary and especially secondary education was limited until 1994, when primary school fees were abolished (virtually overnight) and primary school became accessible to Malawians of all backgrounds. According to Samer Al-Samarrai and Hassan 
Zaman (2007) the abolition of primary school fees resulted in a surge in enrolment from 1.9 million students in 1994 to an all-time high of 2.9 million students in 1999. The expansion of access to primary schools evidently improved the equity of Malawi's primary education system. UNDP estimates that in 2005 Malawi had a net primary enrollment rate of $95 \% .^{4}$ At the same time, expanded access inevitably posed and continues to pose a challenge to the quality of primary education as many primary schools have to cope with shortages of nearly all physical and human resources.

\section{Secondary Education in Malawi}

Education policy in Malawi has primarily focused on improved access to primary education over the past half a century. The resulting expansion of access to primary education, especially in the period after 1994, has put the secondary education system under pressure as the numbers of primary school graduates wishing to attend secondary school have soared. Compared to the primary education system, the capacity of the secondary school system is limited and, at $24 \%$, the 2005 net secondary enrolment rate was among the lowest enrolment rates in the world. ${ }^{5}$

Traditionally, the bulk of secondary education in Malawi was provided in a group of elitist secondary schools, generally referred to as conventional schools. These conventional schools can be subdivided into 24 national boarding schools, 41 district boarding schools, and 52 district day schools. National boarding schools are considered to be the best conventional schools and serve pupils from the entire country. District boarding schools are considered to be the next best group of conventional schools and serve only pupils attending primary schools in the same district. District day schools serve only pupils who live within commutable distance from the school.

\footnotetext{
4 See the Human Development Report country statistics for Malawi: http://hdrstats.undp.org/en/countries/data_sheets/cty_ds_MWI.html. ${ }^{5}$ See footnote 5 .
} 
To increase access to secondary education beyond that provided in conventional schools at a limited cost, the government started to provide secondary education in so-called "distance education centers", which later came to be known as community day schools. The government, in cooperation with various donor organizations and the African Development Bank, is currently working to get the quality of community day schools up to par with conventional schools.

Despite the government's efforts to improve the quality of the community day schools, significant disparities in terms of physical and human resources persist, as illustrated by Table 1 . The table shows that, on average, conventional schools are bigger than community day schools and the disparities in available physical and human resources are large. Community day schools do somewhat better in terms of teacher to pupil ratios, but this result is reversed when teacher education is taken into account. In conventional schools nearly all teachers have obtained a degree beyond the Malawi School Certificate Examination (the MSCE is the degree obtained upon successful completion of secondary school). In community day schools only 1 in 6 teachers has obtained a degree beyond MSCE. Basic physical resources are often lacking in community day schools, while they are available in most conventional schools. Differences in availability of libraries, toilets, and electricity are particularly striking. Conventional schools can, on average, provide each pupil with a book for Chichewa, English, and mathematics, while books for these subjects have to be shared among 2 pupils in community day schools. ${ }^{6}$ These differences do not translate into significantly higher school fees in conventional secondary schools, as school fees are capped by government regulation.

Table 2 shows that the differences in physical and human resources between day and boarding conventional schools are not nearly as pronounced. Differences in the teacher pupil ratio

\footnotetext{
${ }^{6}$ Although conventional schools compare favorably to community day schools, they would still be considered to be unacceptably poorly equipped schools in any western country.
} 
and educated teacher pupil ratio are no longer significant. Significant differences in most of the physical resources are present, but they are an order of magnitude smaller than differences between community day school and conventional school.

The government of Malawi currently primarily attempts to increase access to formal public education by increasing the number of community day schools. The number of conventional schools, on the other hand, is more or less stagnant. Despite the efforts made by the government to expand access to public secondary education, the surge in primary school graduates in the 1990s could not be fully absorbed by the formal public institutions for secondary education (community day schools and conventional schools). As a result private secondary schools mushroomed over the past 15 years.

Private secondary schools cannot be treated as a homogenous group, because they exhibit vast differences in terms of quality and fees. Some private schools provide expensive and high quality education to privileged inhabitants of Malawi's cities. However, the vast majority of private schools are poorly equipped and scantly staffed institutions even in comparison to community day schools. They cater to the average Malawian pupil who was not selected into a community day school or conventional school, and do so at the lowest possible cost. Many private schools are not officially registered or regulated, do not function as exam centers (their pupils have to sit for exams as external candidates at schools that do function as exam centers), and the government knows little about the quality of these schools. In general, unless they can afford to attend fancy upper class private schools, students will prefer to enroll into a community day school or conventional school.

\section{Examination}

Student performance in primary school is assessed based on the PSLCE. The PSLCE tests pupils on 5 subjects: Chichewa, English, mathematics, science, and social studies. Secondary education in Malawi consists of four years of schooling divided into a two-year junior cycle and a 
two-year senior cycle. Student performance in these two cycles is assessed on the basis of the JCE and the MSCE respectively. In the JCE and MSCE students are tested on a subset of 24 course subjects.

The PSLCE, JCE, and MSCE are standardized national exams set and marked by the Ministry of Education and the Malawi National Examinations Board. Besides the grades for individual courses, the Examinations Board also awards students an overall "pass" or "fail" based on the aggregate score of the course subjects examined.

\section{E. Selection Procedures}

The Malawi National Examinations Board exam data show that in 2004 there were 150,748 pupils who sat for the PSLCE out of which 94,789 passed. The ministry of education was able to provide 39,090 of the pupils who passed the PSLCE a spot in one of the public secondary schools (community day schools or conventional schools) for the 2005 school year: 11,900 in conventional schools and 27,190 in community day schools. Because the number of primary school graduates surpasses the number of available spots in public secondary schools the Ministry of Education employs a merit based selection system that uses performance on the PSLCE as a selection criterion. With this system the ministry of education ensures that the top performers on the PSLCE are able to attend the top secondary schools.

Selection into Form 1 (the first grade of secondary school) is conducted by a team of officials from the Ministry of Education and the Division Education Offices (henceforth the selection team). On each of the five course subjects examined in the PSLCE pupils can score a total of 100 points maximum. The selection team generates an aggregate PSLCE score that is the sum of a pupil's scores on his/her 4 best subjects. Based on this aggregate PSLCE score, the selection team then selects pupils into a national boarding school, district boarding school, district day school, or into a community day school. Each school can accommodate a fixed number of boys and a fixed 
number of girls annually. Below I describe the exact procedures used by the selection team to select pupils into the available places in each school type. Appendix 2 provides additional details on the selection procedures.

National boarding schools. - For selection into Form 1 of national boarding schools, pupils are stratified by gender and then selected based on merit. In 2005, for instance, the national boarding schools were able to accommodate 718 male and 773 female pupils. The MOE ranked all male and female students according to their aggregate PSLCE scores and then selected the top 718 male students and the top 773 female students into national boarding school.

The selection team also decides which specific national boarding school each of the selected pupils can enter. This decision is based on the distance of each pupil's primary school to the national boarding schools. As much as possible, the selection team selects pupils into the national boarding school closest to their primary school.

District boarding schools. - For organizational purposes the ministry of education divides Malawi into 33 education districts. Of the 33 districts, 29 have district boarding schools, which are only accessible to students who took the PSLCE in the district. Similar to the selection into national boarding schools, pupils are stratified by gender and then selected into the district boarding schools based on merit.

If there are multiple district boarding schools in a district the selection team decides which specific district boarding school a pupil can attend. To do so, pupils are ranked according to 
aggregate performance within their gender group and then distributed across the district boarding schools in groups of three in descending order. ${ }^{7}$

This procedure ensures that pupil performance on the PSLCE is balanced across district boarding schools.

District day schools. - District day schools do not provide boarding facilities and pupils have to commute (usually walk) to these schools on a daily basis. It is therefore important that pupils are selected into district day schools located within a reasonable distance from their home village.

To ensure that pupils are only selected into nearby district day schools, the selection team selects pupils for each district day school only from so-called feeder schools. Feeder schools are primary schools within commutable distance from the district day school. Pupils who took their PSLCE in a feeder school belonging to a district day school are again stratified by gender and then selected into the corresponding district boarding schools based on merit.

Community day secondary schools. - Finally, the selection team selects pupils into community day schools. Similar to conventional schools, the number of male and female pupils who can enter community day schools is fixed. The procedure used to select pupils into community day schools is equivalent to the procedure used for district day secondary schools.

\footnotetext{
${ }^{7}$ Suppose, for instance, that there are three District Boarding Schools: A, B, and C. The selection team then selects the first three pupils on the list to go to District Boarding School A, the next three pupils to go to District Boarding School $\mathrm{B}$, the next three pupils to go to District Boarding School C, the next three pupils to go to District Boarding School A etc.
} 
Cutoff points. - The number of available places in each school type and the performance of the pupils on the PSLCE together implicitly determine cutoff points in the PSLCE (which differ for boys and girls) to make it into each school type:

1. A national cutoff point to make it into national boarding school;

2. A cutoff point that differs per district to make it into district boarding school;

3. A cutoff point that differs per district day school to make it into district day school;

4. A cutoff point that differs per community day school to make it into community day school.

\section{Methodology}

\section{A. Estimation}

The selection procedure described in the previous section can be interpreted as an application of the regression discontinuity design, which was first introduced by Donald L. Thistlethwaite and Donald T. Campbell (1960) and formalized by Jinyong Hahn, Petra Todd, and Wilbert van der Klaauw (2001). The regression discontinuity design exploits the observed jump in the probability of being selected into a conventional school to estimate the causal effect of selection on school outcomes. It essentially does so by comparing pupils with a PSLCE score right below the cutoff score to those with a PSLCE score right above the cutoff. The identifying assumption is that pupils with a PSLCE score right below the cutoff point are comparable to pupils with an exam score right above the cutoff and thus serve as a valid counterfactual.

Consistent estimation of the treatment effect at the cutoff point requires a correct specification of the relationship between the forcing variable (the PSLCE score) and the outcome of 
interest. I follow the recent empirical regression discontinuity literature and approximate this relationship with a low order polynomial. ${ }^{8}$

Formally, I estimate the following relationship:

$$
Y_{i}=\alpha+\beta T_{i}+\sum_{k} \gamma_{k}\left(X_{i}-c\right)^{k}+\sum_{k} \delta_{k} D_{i}\left(X_{i}-c\right)^{k}+\varepsilon_{i}
$$

where $Y_{i}$ is the schooling outcome of interest (e.g. passing the JCE) for pupil $i . T_{i}$ is a dummy that takes the value 1 if pupil $i$ was selected into a conventional school. The term $\sum_{k} \gamma_{k}\left(X_{i}-c\right)^{k}$ is a polynomial of order $k$ that estimates the relationship between the outcome of interest and the distance of a pupil's PSLCE score $X_{i}$ (the forcing variable) to the cutoff score $c$. The term $\sum_{k} \delta_{k} D_{i}\left(X_{i}-c\right)^{k}$ includes $D_{i}$, a dummy that takes the value 1 if a pupil's exam score exceeds the cutoff point $c$, and thus allows for a different functional form of the polynomial above and below the cutoff score. $\varepsilon_{i}$ captures all other determinants of passing the JCE. As I will show in the results section, the selection procedures are executed with some imprecision. I therefore apply the so-called "fuzzy" version of the regression discontinuity design, which accommodates for imprecise selection by instrumenting for selection into a conventional school $\left(T_{i}\right)$ with having an exam score beyond the cutoff score $\left(D_{i}\right)$.

The coefficient $\beta$ gives the intent-to-treat effect - the effect of being selected into a conventional secondary school. An attractive feature of the regression discontinuity design is that this intent-to-treat effect can not only be estimated econometrically, but also conveyed graphically.

\section{B. Multiple Cutoff Points}

A limitation of the standard regression discontinuity design with only 1 cutoff point is that it provides only a local estimate of the treatment effect. The selection into conventional school differs

\footnotetext{
${ }^{8}$ See Jordan D. Matsudaira (2008) and Damon Clark (2009) for recent applications of this parametric RD approach in the economics of education literature. See Guido W. Imbens and Thomas Lemieux (2008) and David S. Lee and Thomas Lemieux (2009) for in-depth "how-to" guides.
} 
from the standard regression discontinuity design, as there are geographic differences in the cutoff point. Differences in the cutoff points across districts provide a rare opportunity to estimate an average treatment effect over a range of the PSLCE scores. I follow the terminology of Dan Black, Jose Galdo, and Jeffrey Smith (2005), who also investigate a situation with multiple cutoff points, and call each group of pupils facing the same cutoff point (e.g. all pupils in feeder schools for the same district day school) a regression discontinuity group. I pool the data from all different regression discontinuity groups and estimate the model described above, with the inclusion of dummies for all regression discontinuity groups to capture fixed effects.

\section{Data}

This paper is based on data extracted from five institutional databases: the 2004 PSLCE scores, the 2006 JCE scores, the 2005 Form 1 selection, and the 2005 and 2006 Education Management Information System (EMIS). ' The 2004 PSLCE scores and the 2006 JCE scores contain personal information (student number, name, and gender), information on the exam center (name, district, type), and exam information (scores on individual subjects on a scale of $1-100^{10}$, aggregate scores, and overall pass/fail) for each pupil. The 2005 selection data contain personal information for each pupil who was selected into a public secondary school (student number, name, and gender) and information on the school these pupils have been selected into (name, district, and type). The 2005 and 2006 EMIS data contain a wide range of school specific information including physical and human resources.

It is fairly straightforward to link most of these datasets on unique identifying variables. The 2005 Form 1 selection data, for instance, can be matched to the 2004 PSLCE data on the basis of a

\footnotetext{
9 The data were kindly provided by Malawi's Ministry of Education and the Malawi National Examinations Board. 10 Pupils themselves never see the 1-100 scores. Instead the scores on the 1-100 scale are converted to abc grades, which are presented to the pupils.
} 
unique student id. Similarly, the EMIS data can be matched to the exam data based on school name, school location and school type.

However, linking the exam scores for individual students across different time periods requires a more involved matching procedure. The 2006 JCE data contain three identifying variables for each pupil: secondary school attended by the pupil, pupil gender, and pupil name. After merging with the 2005 Form 1 selection data, the 2004 data contain these same three identifying variables. ${ }^{11}$ Nevertheless, for many of pupils, an exact match on these three identifying variables is impossible because of differences in the spelling of their names across different years.

To deal with the issue of differently spelled names I applied an "approximate string matching procedure". I have been conservative in my procedure to accept approximate string matches and checked all approximate string matches manually. A detailed description of this string matching procedure can be found in appendix 1. The available data and variables are equivalent for community day schools and conventional schools and come from the same datasets. As a result the matching procedure is identical for pupils selected into community day schools and conventional schools.

\section{Results}

\section{A. Selection into Form 1}

The 2004 PSLCE Exam Scores and the official selection procedures described can be used to reconstruct the selection into form 1 for the 2005 school-year. In this section I graphically compare these reconstructed selection results to the actual selection conducted by the selection team

\footnotetext{
11 There is one important distinction though: whereas the 2006 JCE data contain the secondary school actually attended by the student, the 2004 PSLCE data contain the secondary school that a pupil was selected into by the MOE.
} 
to gain insight into the precision with which the selection team executes its own selection procedures.

Figs. 1a and $1 \mathrm{~b}$ compare the actual results for selection into form 1 of a conventional school (national boarding school, district boarding school, or district day school) in 2005 to the reconstructed selection results for boys and girls respectively. As described, the cutoff point for selection into a conventional school differs per district and even within districts. To investigate the average precision of the selection procedure (rather than the precision at each individual cutoff point) all PSLCE scores are centered in Figs. $1 \mathrm{a}$ and $1 \mathrm{~b}$ such that they take the value zero at the relevant cutoff point.

The scores on the horizontal axis indicate the distance of the aggregate PSLCE scores to the relevant cutoff point in the aggregate PSLCE scores. Negative scores indicate the extent to which the aggregate PSLCE score falls short of the cutoff point (in standard deviations) and vice versa for positive scores. The vertical axis depicts the fraction of PSLCE takers actually selected to enter form 1 of a conventional school in 2005. The points depict the fraction of pupils selected into conventional school at each integer distance from the cutoff point. The fitted lines above and below the cutoff score are quadratic regressions. ${ }^{12}$

Two conclusions can be drawn from these graphs. First, the probability of being selected into a conventional school exhibits a pronounced jump at the cutoff point for both boys and girls. Second, the actual selection does not concur one for one with the reconstructed selection, which implies that the selection team does not precisely follow the official procedures. If the team had precisely followed the procedures, the fraction of pupils selected into conventional school would

\footnotetext{
12 Similar Figures were used by Lee (2008) and I follow his example.
} 
have been 0 at all values below the cutoff point (the negative scores on the horizontal axis) and 1 at all values above the cutoff point. ${ }^{13}$

\section{B. Passing the Secondary School Exam}

Figs. 2a and $2 \mathrm{~b}$ illustrate the impact of selection into a conventional school after completion of the 2004 PSLCE on the probability of successfully completing the JCE exam in 2006. The horizontal axis again measures the distance of the aggregate 2004 PSLCE score to the 2004 cutoff score. The vertical axis measures the fraction of pupils who successfully completed the JCE in 2006 in the school into which they were selected.

Fig. 2a displays a clear jump at the cutoff point. Boys whose PSLCE score lies just above the cutoff point have a noticeably higher probability of passing the JCE in 2006 than boys whose PSLCE score lies just below the cutoff point. Fig. 2b displays a similar, albeit less pronounced, discontinuity in the probability of girls passing the JCE in 2006. Overall, Figs. 2a and 2b present strong evidence of the positive impact of selection into a conventional school on the probability of successfully completing the JCE two years after taking the PSLCE.

Column (1) of Table 3 presents fuzzy RD estimates of the positive treatment effect visible in Figs $2 \mathrm{a}$ and $2 \mathrm{~b}$ for both boys and girls. Standard errors are given in parentheses. In accordance with general conventions in the $\mathrm{RD}$ literature the table displays estimates based on several orders of polynomials to investigate the robustness of the estimated treatment effects to misspecification. Following Lee and Lemieux (2009), I determine the optimal order of the polynomial based on the Akaike information criterion (AIC).

\footnotetext{
13 The difference between the pupils actually selected and those who should have been selected if the selection team had precisely applied its own selection procedures might be caused by imprecise technical execution of the procedures. At this point I have no evidence for any other explanation.
} 
The results presented in Table 3 are in accordance with Figs. $2 \mathrm{a}$ and $2 \mathrm{~b}$. The impact of selection into conventional school on the probability of passing the JCE in 2 years is positive and significant for boys and girls in all specifications. For boys, depending on the specification used, the probability of passing the JCE in 2006 exhibits a jump of 18 to 27 percentage points. For girls, the probability exhibits a jump of 21 to 29 percentage points. Overall, the evidence for a positive treatment effect of selection into conventional school is strong. For the optimal order of the polynomial, the estimated treatment effect equals a roughly $50 \%$ higher probability of successfully completing the JCE for pupils with a PSLCE score just above the cutoff point.

\section{Pupil Retention}

The discontinuity in the probability of passing the JCE can be split up into two components: (i) the probability of participating in the JCE in the school a pupil was selected into two years after taking the PSLCE and (ii) the probability of passing the JCE conditional on participating. I interpret the first component as an indication of the extent to which conventional schools do a better job at retaining their pupils. The second component gives an indication of the extent to which selection into a conventional school affects pupil learning.

Figs. $3 \mathrm{a}$ and $3 \mathrm{~b}$ illustrate the impact of selection into conventional school on the first component (pupil retention). The vertical axis measures the fraction of pupils retained. Both graphs again exhibit a clear jump at the cutoff point. The percentage of pupils retained is visibly higher among boys and girls with a PSLCE score right above the cutoff point.

Column (2) of Table 3 confirms these observations. For boys, depending on the specification used, the retention rate exhibits a jump of 25 to 29 percentage points. For girls, the retention rate exhibits a jump of 28 to 32 percentage points. For the optimal order of the polynomial, the estimated treatment effects correspond to a roughly 50\% higher retention rate among pupils with a PSLCE score just above the cutoff score. 


\section{Pupil Learning}

At first sight, selection into conventional school does not appear to have a similar impact on the second component of passing the JCE: pupil learning. Figs. $4 \mathrm{a}$ and $4 \mathrm{~b}$ do not exhibit a jump in the conditional probability of passing the JCE at the cutoff point. Column (3) of Table 3 displays a similar ambiguity. In all but one of the specifications we do not observe a statistically significant jump in pupil learning.

Based on the presented evidence, it is tempting to conclude that, compared to community day schools, conventional schools do a better job at keeping children in school, but not at teaching their pupils. This conclusion is valid only if pupils who could not be retained by community day schools, but who would have been retained by conventional schools, do not differ from pupils retained by community day schools in terms of their conditional passing probability. However, it is likely that these pupils actually have a lower conditional passing probability, as a lower conditional passing probability can be one of the reasons for pupils to discontinue their secondary education. Hence, Figs. 4a and 4b, as well as column (3) of Table 3, probably represent an underestimate of the impact of selection into a conventional school on pupil learning.

It is possible to estimate an upper bound on the impact of selection into a conventional secondary school, based on the assumption that all additional pupils that community day schools would have to retain to achieve a pupil retention rate comparable to that of conventional schools would fail the JCE. Column (4) of Table 3 estimates this upper bound, by artificially adding pupils to the community day school data such that, on average, community day schools and conventional schools have the same fraction of participating pupils at the cutoff point. All of the artificially added pupils are classified as failing for the exam, which effectively pushes down the fraction of pupils passing the exam conditional on participating in community day schools. The results, displayed in column (4), differ drastically from those in column (3). Depending on the order of the polynomial, 
the number of pupils passing the JCE conditional on participating in conventional schools is now 31 to 46 percentage points higher for male pupils and 44 to 78 percentage points for female pupils.

Because I have no further information on pupil backgrounds and capabilities, it is hard to say whether the true estimate is closer to the estimated upper bound. The results from this wide bounds analysis suggest that, at worst, conventional schools keep a markedly higher fraction of pupils in school without a deterioration in pupil learning. At best, conventional schools manage to keep a much higher fraction of pupils in school and simultaneously improve pupil learning.

\section{E. Heterogeneity}

The results presented thus far represent average treatment effects across a large range of cutoff scores. Table 4 provides insight into possible heterogeneity of the treatment effect across cutoff scores. It displays the estimated impact of selection into conventional school on pupil retention across 8 ranges of the cutoff scores faced by pupils to be selected into conventional schools. The ranges each represent roughly $12.5 \%$ of the pupils selected into a public secondary school.

Column (1) shows that the normalized cutoff scores range from roughly minus 2 standard deviations from the mean PSLCE score to almost plus 2 standard deviations from the mean PSLCE score for both boys and girls. Column (2) shows the exact number of pupils in each cutoff range and column (3) provides the estimated treatment effect for each range. The estimated treatment effect appears to be somewhat volatile. However, it is positive over the entire range of cutoff scores and, despite the fact that sample sizes are now much smaller than for the pooled data, often statistically significant. Overall, the results strongly suggest that the impact of selection into conventional school on pupil retention is present over a large range of cutoff points and not merely local. 


\section{Validity and Robustness}

\section{A. Validity}

David S. Lee (2008) showed that, when optimizing agents do not have precise control over the forcing variable, the variation in the treatment will be as good as random around the cutoff point. In such cases the $\mathrm{RD}$ design provides a transparent approach to estimate causal program effects. However, ability of agents to precisely manipulate the forcing variable may lead to endogenous sorting around the cutoff point and invalidate the RD approach.

Pupils taking the PSLCE are a prime example of agents who do not have precise control over the forcing variable. First, they do not know their own exam score when they are taking the exam (i.e. they do not have precise control over the forcing variable). Second, the cutoff point is only determined after all exams have been administered and corrected, so the people hired to correct the exams do not know the cutoff score either. Precise sorting around the cutoff score is, therefore, virtually impossible.

Justin McCrary (2008) proposed to test directly for any manipulation of the forcing variable by inspecting the density of the forcing variable for any discontinuities around the cutoff point. In case of endogenous sorting, we would expect the density of the forcing variable to be discontinuous around the cutoff score: a disproportionately large number of pupils would have a PSLCE score just above the cutoff point and vice versa below the cutoff point.

Figs. 5a and 5b provide an eyeball test of the extent to which pupils sort around the cutoff score. They display the density of the distance of the aggregate PSLCE score to the cutoff score. As 
expected, Figs $5 \mathrm{a}$ and $5 \mathrm{~b}$ provide no evidence of endogenous sorting. The density is a smooth function and does not exhibit a significant jump around the cutoff score. ${ }^{14} 15$

\section{B. Robustness}

There may be variation in the estimated impact of selection into a conventional school on pupil retention for different subgroups and as a result the pooled regressions could mask important underlying disparities in the treatment effect. This subsection investigates four important possible sources of heterogeneity in the impact of selection into a convention school on school participation.

Boarding vs. Day Conventional Schools. - The treatment effects estimated in the previous section combine the data for boarding and day conventional schools. However, the treatment effects could be more pronounced in one of these conventional school types, which could lead to the incorrect conclusion that conventional schools in general do a better job at preventing pupils from dropping out or repeating grades.

Since pupils are selected into boarding conventional school according to merit there is a cutoff point for selection into boarding conventional school versus selection into day conventional school. Table 5 presents results for the impact of selection into boarding conventional school versus day conventional school on retention rates. The estimates do not appear to be robust to changes in

\footnotetext{
14 The Figures display a Lowess regression rather than a parametric regression and illustrate the importance of choosing the correct functional form of the parametric regressions. Approximation of these functions with a linear or quadratic function would lead to the conclusion that the density exhibits a significant jump at the cutoff point, simply because a linear or quadratic function does not fit the true functional form.

${ }^{15}$ For both boys and girls we do observe a small jump right at the cutoff point. This jump is related to the procedure used to regenerate the cutoff points and does not reflect any endogenous sorting. By definition the cutoff point is determined by those who have the lowest score to make it into conventional school (i.e. those with the lowest score to make it into conventional school serve as a reference point for all other observations). As a result there are pupils with this score in every RD group, whereas at other scores some of the RD groups have no observations. As a result there is a jump right at the cutoff point.
} 
the order of the polynomial and exhibit large swings. However, none of the estimated treatment effects is statistically significant. ${ }^{16} 17$

The results in Table 5 suggest that the impact of selection into a conventional school on retention cannot be attributed to either day or boarding schools. The lack of evidence for superior performance of boarding schools in terms of pupil retention is of interest in itself. Boarding schools are an important feature of the education system in many Sub-Saharan countries. They are generally considered to be the top notch schools, although little is known about their relative performance. The results presented in Table 5 provide little evidence to support the superior reputation of boarding schools, at least in terms of pupil retention.

Tumbuka Northern Region vs. Rest of the Country. - The north of Malawi is primarily inhabited by the Tumbuka, a Bantu tribe. In Malawi, the Tumbuka are renowned for the value they attach to education and for their performance in school. If there are performance differentials between Tumbuka pupils and other pupils the estimated overall treatment effects might not be representative for either Tumbuka pupils or other pupils.

To investigate this issue, I separately re-estimate the impact of selection into conventional school on retention rates for pupils from the north of Malawi and for all other pupils. Column (1) of Table 6 presents the original pooled estimates, column (2) presents the estimates for pupils from the Northern region, and column (3) presents the results for pupils from the other regions. A Chow test

\footnotetext{
${ }^{16}$ Other results for the differences between day and boarding conventional school resemble results for differences between community day school and conventional school. There is still a pronounced jump in the probability of being selected at the cutoff point, whereas there is no jump in the probability of passing the JCE conditional on participating in the JCE. I do not present these results, but they are available on request.

${ }^{17}$ The lack of a significant jump at the cutoff point for selection into boarding conventional school is in accordance with the hypothesis that the probability of dropping out or repeating grades is to a large extent driven by the educated teacher pupil ratio rather than issues unrelated to school quality. As table 2 illustrates, there are no significant differences in the educated teacher pupil ratio or the teacher pupil ratio between day and boarding conventional school. Hence, if educated teacher pupil ratios play an important role in the probability of dropping out, we should not expect to find a significant discontinuity.
} 
provides no evidence for a statistically significant difference between the parameters estimated for the two groups and those estimated using the pooled data. There is thus no evidence that the estimated average treatment effects are driven by Tumbuka pupils.

Urban vs. Rural Schools. - There could be differences in the impact of selection into conventional school on retention rates between urban and rural conventional schools. Columns (4) and (5) of Table 6 respectively present estimates for the impact of selection into urban and rural conventional schools on pupil retention. Both urban and rural conventional schools consistently and significantly outperform their community day counterparts in terms of pupil retention. The point estimates of the estimated treatment effect, however, are consistently higher for pupils selected into urban conventional schools. The Chow test confirms that the parameters estimated for the sample of pupils selected into urban conventional schools differ significantly from those estimated for the pooled data.

Errors in From 1 Selection. - As discussed in section IV, the selection conducted by the selection team does not concur one for one with the reconstructed selection. If the pupils who were incorrectly selected into community day school or conventional school do not constitute a random group, their inclusion in the analysis may distort the estimated treatment effects. Column (6) of Table 6 shows the impact of selection into conventional school on the probability of taking the JCE using only data for pupils who were correctly selected into conventional schools. Removing incorrectly selected pupils from the data barely affects the point estimates of the treatment effect and a Chow test provides no evidence for a statistically significant difference in the parameters. 


\section{Conclusion}

This paper provides the first evidence on the impact of large scale tracking policies in SubSaharan Africa on school outcomes. The results indicate that a tracking policy in Malawi has a substantial impact on pupil retention. Relatively well-endowed conventional secondary schools, which accommodate the country's top pupils, keep roughly $50 \%$ more pupils in school than other public secondary schools. The strong impact of the tracking policy on pupil retention is not merely a local effect, but present across a large range of the pupil ability distribution. Moreover, a bounds analysis suggests that pupil learning in conventional schools is at least equal to, but possibly markedly higher than in community day schools.

Robustness checks show that the impact of the tracking procedure is (i) not driven by boarding schools, (ii) not likely to be driven by students from one particular tribe, and (iii) more pronounced in urban areas. The fact that boarding schools do not improve pupil retention is an important finding in itself, as boarding schools form an integral part of secondary education in many Sub-Saharan countries. The finding suggests that boarding facilities are not a viable solution to the difficulties faced by schools in Sub-Saharan Africa to keep pupils in school.

The results presented in this paper are relevant for policy makers in Sub-Saharan countries that employ tracking policies similar to the one employed in Malawi, or that consider adopting such tracking policies. Although Malawi's tracking policy positively affects those pupils selected into conventional schools, the results do not necessarily imply that overall education outcomes are improved by this policy. It may well be the case that a more equal distribution of pupils and resources across all secondary schools positively affects pupils in community day schools to the extent that nation-wide pupil retention rates actually increase. The presented results should thus not be interpreted as a plea in favor of tracking policies. 
What the results do tell is that tracking policies can have a substantial impact on top pupils selected into the elite schools. If policy makers worry that spreading limited resources across a large number of schools will render the scarce resources ineffective, the effect of concentrating the resources in a smaller number of selective schools can be substantial.

There are two potential explanations for the fact that this paper finds a strong relationship between the school environment and school participation, while previous evidence for such a relationship is limited. First, this paper studies a comprehensive measure of the school environment, including virtually all aspects of peer and school quality. Most other studies focus on a single aspect of school quality, such as the pupil teacher ratio. The advantage of this comprehensive measure is that it is much more likely to capture any effect of the school environment on pupil retention. The obvious disadvantage is that it is impossible to say which components of the school environment explain the effect on pupil retention. Further research disentangling these components will therefore be highly relevant.

Second, this paper studies secondary schools while most of the available literature focuses on primary schools. It is likely that the secondary school environment plays a more important role in keeping pupils in school than the primary school environment. As pupils grow older and their outside opportunities and obligations (such as work, marriage, and children) increase, they will start to evaluate the usefulness of attending school more critically. This process may explain why the secondary school environment has such a pronounced impact on pupil retention in Malawi and suggests that a focus on school quality may be a valuable complement to more traditional policies that attempt to improve secondary school participation (such as conditional cash transfers and reductions in school fees).

Finally, it is worth emphasizing a potential caveat. While I observe the schools into which pupils are selected, I do not observe the schools they actually enter. If pupils are able to circumvent 
the official selection procedures by entering other schools than the ones into which they were selected this can affect the results presented in this paper. Similarly, the results may be affected if pupils are able to avoid participating in the JCE while continuing their education. That being said, I do not have an indication of evasion of the official selection procedures or the JCE by pupils. It also appears implausible for the Ministry of Education to maintain its selection procedure and obligatory examinations such as the JCE, both of which impose a substantial organizational burden on Malawi's education sector, if pupils are known to evade the rules on a large scale.

\section{APPENDIX 1: COMBINING INSTITUTIONAL DATA}

\section{Matching Procedure}

This appendix provides a detailed description of the approximate string matching procedure for PSLCE and JCE scores.

In the first step of this procedure I directly merged the PSLCE data and the JCE data on the three identifying variables. This step gave a total of 5,442 successful exact matches on all identifying variables out of the initial 39,090 pupils for whom PSLCE and selection information is available.

In the second step I first split the variable student name for all remaining pupils up into all of its constituent names (e.g. the observation "Banda William James" is split up into the three new variables "Banda", "William", and "James"). I then directly merged on secondary school, gender and all possible combinations of 2 of the constituent names. In other words, in this step I considered an exact mach on secondary school, gender, and two of the constituent names to be a sufficient condition to merge. This step gave an additional 8,855 additional matches. 
I did not manually check all additional matches, but I did inspect a sample of 100 of the additional matches. In the sample I inspected, the majority of matches did not lead to a match in step 1 for the following four reasons:

1. Different spelling of some of the constituent names;

2. Different use of abbreviations in some of the constituent names;

3. Different ordering of the constituent names;

4. Exclusion of one or more of the constituent names in one of the years.

In the sample there were 8 pupils for whom one of the constituent names differed across the years (e.g. one of the constituent names is Phazani in one year and Rodgers in the next). Two out of these 8 students had a different Surname, whereas the remaining pupils had a different given name.

It is hard to say what the correct approach is to dealing with these problem cases (i.e. those for whom one of the constituent names truly differed across the years). Names are a fluid concept in Malawi. From personal experience with household and school surveys in Malawi, I know that it is not uncommon for pupils to change their names, to be known by multiple given names, or to use and adopt different (nick) names over time. Moreover, surnames can change when pupils get married or lose their parents.

I chose to treat an exact match on secondary school, gender, and two of the three constituent names as a sufficient condition to merge. An alternative approach could, for example, be to drop all problem cases. However, I expect that the latter procedure would drop many legitimate matches and relatively few incorrect matches.

In the third step I used approximate string matching to match observations for which no exact match of names came up in steps 1 and 2 on secondary school, gender, and name. The 
software I used (called reclink) was written for Stata by Michael Blasnik ${ }^{18}$ and "combines approximate string comparators and probabilistic matching algorithms to identify the best matches and assess their reliability".

The matching algorithm provides a match score that indicates how closely two observations match on a scale from 0 to 1 . By default, the program discards all matches with a match score below 0.6 and I maintained this default. I manually checked all matches. In this step, as in step 2, I considered a close match on two constituent names to be a minimum requirement. I discarded all combinations based on less than two close matches.

Manually checking matches is a tedious and somewhat arbitrary job. In the process I may have discarded some matches that others would not have discarded and vice versa. However, in the vast majority of cases the success of the matching algorithm is fairly easily determined and not controversial. Just to give an example, most people would agree that the names "Lazalo Christina Daisoni" and "Dayisoni Christina L" constitute a reasonable match, whereas the names "Genda Eric Henry" and "Banda Henry C" do not.

After manually discarding 513 mismatches, step 3 gave an additional 4,930 matches.

I did not match to the remaining pupils, although some of them will have taken the JCE in a school other than the one they were selected into. The reason for this decision is that, because the number of names to be matched is large, it is virtually impossible to tell whether a close match in terms of names really does constitute a legitimate match.

\section{Success of the Matching Procedure}

\footnotetext{
${ }_{18}$ Blasnik, M. (2007). Reclink: Stata module to probabilistically match records. EconPapers software: http://econpapers.repec.org/software/bocbocode/s456876.htm.
} 
According to the EMIS, only about $60 \%$ of the pupils who entered public secondary school in 2005 should show up in the 2006 JCE records for the school that they had been selected into. The remaining pupils should not show up for the following reasons: $15 \%$ of them drop out in Form 1, 1\% repeat Form 1, 5\% transfer to another school during Form 1, 13\% drop out in form 2, 7\% repeat Form 2, 3\% transfer to another school during Form 2.

There will also be a group of pupils who do not show up in the 2006 JCE records, because they never enter the public secondary school they had been selected into. Some of them will be pupils who decided never to attend secondary school, regardless of their selection into a public secondary school. Others will be pupils who transferred to another secondary school before the start of Form 1. Finally, there will be pupils do not show up in the 2006 JCE records because they registered for the 2006 JCE under a completely new name.

Although I cannot provide exact percentages for the latter 3 reasons (because they are not part of the EMIS data), it seems unlikely that much more than $50 \%$ of the pupils selected to attend Form 1 in community day school or conventional school in 2005 will show up in the 2006 JCE records. Indeed, the matching procedure matched the 2004 PSLCE score to the 2006 JCE score for $49 \%(19,227$ out of 39,090$)$ of these pupils. The selection procedure thus appears to have been successful. Depending on the percentages for the latter 3 reasons, the success rate is at least $82 \%$, but probably close to $100 \%$.

APpendix 2: AdDitional INFORMATION ON SELECTION PROCEDURES

\section{Tie-Breaking PSLCE Scores}

Because entry quotas for school types are fixed they implicitly determine the PSLCE cutoff points. There may be cases where only a fraction of pupils at the cutoff point can be selected. As an 
example, consider the 2005 national boarding school selection. A total of 718 boys were to be selected into national boarding school and the resulting cutoff point in the aggregate PSLCE score was 268. Because the top 716 to 766 male pupils all had an aggregate PSLCE score of 268 only 3 of the pupils at the cutoff point could be selected.

The selection team deals with this issue by ranking all pupils with an aggregate PSLCE score equivalent to the cutoff score in ascending alphabetical order. The pupils are then selected according to this order until the quota is reached, which implies that those with a name that starts with a letter early in the alphabet have a slightly higher chance of being selected. In the regression discontinuity literature designs where treatment is randomly assigned at the cutoff point are generally referred to as tie-breaking experiments.

\section{What if Selected Pupils do not Enroll}

Some of the pupils who were selected into a government secondary school will, for a number of reasons, decide not to attend the school they have been selected into. The MOE follows a straightforward procedure to deal with this issue. When a place is freed up in one level the top ranked pupil from the level below is pushed up a level. There is a waiting list for Community Day Secondary Schools, so pupils who were originally not selected into any government secondary school can attend Community Day Secondary School if places are freed up.

\section{Switching Between Schools of the Same Level}

It is, in principle, possible for pupils to apply for a transfer to another school within the same level. Pupils can hand in a request to be transferred to another school of the same level at the Division Education Office. The officer in charge will pass the request on to the school the pupil 
wants to transfer to. The school under consideration then lets the Division Education Office know if they have space for this additional pupil.

\section{Switching Between Schools of a Different Level}

For a variety of reasons, some of the students will attempt to transfer to a school of a lower

level. Applying to a school of a lower level is discouraged by the District Education Offices. However, if a pupil insists on switching to a school of a lower level the Division Education Office has the ability to permit the transfer.

Some pupils who have been selected into District or National boarding school will apply for a transfer to a lower level school (e.g. a non-boarding school), because they cannot afford to pay the boarding fees. Some bursaries are available for these students through the secondary school bursary scheme (formerly known as GABLE). ${ }^{19}$ Nevertheless the District Education Office will sometimes have to grant the request to be selected into a lower education level.

There are also pupils who will attempt to be accepted into a school of a higher level. The Division Education Office has some discretion to grant such requests if students provide compelling reasons for the transfer. Compelling reasons can, for instance, be physical disabilities that hamper a pupil's performance in the PSLCE.

${ }^{19}$ For additional information refer to http:/ /www.sdnp.org.mw/edu/fees-edu-sec.html. 


\section{REFERENCES}

African Development Fund. 2001. "Support to Community Day Secondary Schools (Education IV Project).” Republic of Malawi, Country Department, Southern Region.

Al-Samarrai, Samer, and Hassan Zaman. 2007. "Abolishing School Fees in Malawi: The Impact on Education Access and Equity." Education Economics, 15(3): 359-375.

Angrist, Joshua D., and Victor Lavy. (1999). “Using Maimonides' Rule to Estimate the Effect of Class Size on Scholastic Achievement.” Quartertly Journal of Economics, 114(2): 533-575.

Banerjee, Abhijit V., Shawn Cole, Esther Duflo, and Leigh Linden. 2007 "Remedying Education: Evidence from Two Randomized Experiments in India." Quarterly Journal of Economics, 122(3): 1235-1264.

Banerjee, Abhijit V., Suraj Jacob, and Michael Kremer. 2000. "Promoting School Participation in Rural Rajasthan: Results from Some Prospective Trials.” Mimeo, MIT.

Black, Dan, Jose Galdo, and Jeffrey Smith. 2005. "Evaluating the Regression Discontinuity Design Using Experimental Data.” Working Paper.

Case, Anne, and Angus Deaton. 1999. "School Inputs and Educational Outcomes in South Africa." Quarterly Journal of Economics, 114(3): 1047-1084.

Clark, Damon. 2009. "The Performance and Competitive Effects of School Autonomy." Journal of Political Economy, 117(4): 745-783.

Ding, Weili, and Steven F. Lehrer. 2007. "Do Peers Affect Student Achievement in China's Secondary Schools?" Review of Economics and Statistics, 89(2): 300-312.

Duflo, Esther, Pascaline Dupas, and Michael Kremer. 2008. "Peer Effects and the Impact of Tracking: Evidence from a Randomized Evaluation in Kenya.” NBER Working Paper No. 14475. 
Glewwe, Paul. 2002. "Schools and Skills in Developing Countries: Education Policies and Socioeconomic Outcomes." Journal of Economic Literature, 40(2): 436-482.

Glewwe, Paul, and Michael Kremer. 2006. "Schools, Teachers, and Education Outcomes in Developing Countries." In Vol. 2, Handbook of the Economics of Education.

Glewwe, Paul, Michael Kremer, and Sylvie Moulin. 2000, “Textbooks and Test Scores Evidence from a Prospective Evaluation in Kenya.” Working Paper.

Hahn, Jinyong, Petra Todd, and Wilbert Van der Klaauw. 2001. "Identification and Estimation of Treatment Effects with a Regression Discontinuity Design.” Econometrica, 69(1): 201-209.

Hoxby, Caroline. 2000. "Peer Effects in the Classroom: Learning from Gender and Race Variation.” NBER Working Paper 7867.

Imbens, Guido. W., and Thomas Lemieux. 2008. "Regression Discontinuity Designs: A Guide to Practice." Journal of Econometrics, 142(2): 615-635.

Lavy, Victor, Daniele Paserman, and Analia Schlosser. 2007. "Inside the Black Box of Ability Peer Effects: Evidence from Variation in High and Low Achievers in the Classroom." NBER Working Paper 14415.

Lee, David S. 2008. "Randomized Experiments from Non-Random Selection in U.S. House Elections." Journal of Econometrics, 142(2): 675-697.

Lee, David S., and Thomas Lemieux. 2009. "Regression Discontinuity Designs in Economics." NBER Working Paper 14723.

Lyle, David S. 2007. "Estimating and Interpreting Peer and Role Model Effects from Randomly Assigned Social Groups at West Point.” Review of Economics and Statistics, 89(2): 289-299.

Matsudaira, Jordan D. 2008. "Mandatory Summer School and Student Achievement." Journal of Econometrics, 142(2): 829-850. 
McCrary, Justin. 2008. "Manipulation of the Running Variable in the Regression Discontinuity Design." Journal of Econometrics, 142(2): 698-714.

Ministry of Education. 2005. "Education Statistics.” Government of Malawi.

Rivkin, Steven. G., Eric. A. Hanushek, and John. F. Kain. 2005. "Teachers, Schools, and Academic Achievement." Econometrica, 73(2): 417-458.

Sacerdote, Bruce. 2001. "Peer Effects with Random Assignment: Results for Dartmouth Roommates." Quarterly Journal of Economics, 116(2): 681-704.

Thistlethwaite, Donald L., and Donald T. Campbell. 1960. "Regression-Discontinuity Analysis: An Alternative to the Ex-Post Facto Experiment.” Journal of Educational Psychology, 51(6): 309317.

UNDP. 2005. “Toward Universal Primary Eduction: Investments, Incentives, and Institutions.” UN Millennium Project, Task Force on Education and Gender Equality.

United Nations. 2008. “The Milennium Development Goals Report.” New York.

Zimmerman, David J. 2003. "Peer Effects in Academic Outcomes: Evidence from a Natural Experiment." Review of Economics and Statistics, 85(1): 9-23. 
Tables

Table 1: School size, physical resources, and human resources in community day schools and conventional secondary schools

\begin{tabular}{|c|c|c|c|c|c|c|c|c|}
\hline & \multicolumn{3}{|c|}{ Community Day Schools } & \multicolumn{3}{|c|}{ Conventional Schools } & \multirow[b]{2}{*}{ T-Stat } & \multirow[b]{3}{*}{$* * *$} \\
\hline & $\mathbf{N}$ & Mean & SE & $\mathbf{N}$ & Mean & SE & & \\
\hline School size (number of pupils) & 453 & 178 & 4.7 & 113 & 460 & 26.3 & -10.55 & \\
\hline \multicolumn{9}{|l|}{ Income } \\
\hline Annual school fees per student in US Dollar & 453 & 25 & 12.2 & 113 & 64 & 39.7 & -0.96 & \\
\hline Annual school income per student in US Dollar & 453 & 97 & 25.3 & 113 & 160 & 63.8 & -0.92 & \\
\hline \multicolumn{9}{|l|}{ Human Resources } \\
\hline Teachers per 100 pupils & 453 & 5.6 & 0.1 & 113 & 4.4 & 0.1 & 7.33 & $* * *$ \\
\hline Educated teachers per 100 pupils & 453 & 0.8 & 0.1 & 113 & 4.0 & 0.1 & -22.89 & $* * *$ \\
\hline Non-teaching staff per 100 pupils & 453 & 0.9 & 0.1 & 113 & 2.6 & 0.2 & -9.61 & $* * *$ \\
\hline \multicolumn{9}{|l|}{ Physical Resources } \\
\hline Percentage of schools with a library & 454 & 35 & 2.2 & 113 & 88 & 3.0 & -14.30 & $* * *$ \\
\hline Percentage of schools with a PC room & 454 & 4 & 0.9 & 113 & 47 & 4.7 & -8.88 & $* * *$ \\
\hline Percentage of schools with toilets & 454 & 4 & 0.9 & 113 & 79 & 3.9 & -19.00 & $* * *$ \\
\hline Percentage of schools with water from tap or borehole & 453 & 78 & 1.6 & 113 & 89 & 2.4 & -3.63 & $* * *$ \\
\hline Percentage of schools with electricity & 453 & 22 & 1.8 & 113 & 82 & 3.2 & -16.31 & $* * *$ \\
\hline Classrooms per 100 pupils & 453 & 2.91 & 0.09 & 113 & 2.36 & 0.11 & 4.00 & $* * *$ \\
\hline Book to pupil ratio (Chichewa) & 425 & 0.49 & 0.03 & 101 & 0.82 & 0.11 & -2.88 & $* *$ \\
\hline Book to pupil ratio (English) & 425 & 0.54 & 0.02 & 101 & 1.11 & 0.14 & -4.13 & $* * *$ \\
\hline Book to pupil ratio (mathematics) & 425 & 0.47 & 0.03 & 101 & 1.08 & 0.14 & -4.25 & $* * *$ \\
\hline
\end{tabular}

Source: EMIS 2005 and EMIS 2006. Schools included are those for which the Ministry of Education selected the 2005 Form 1 pupils. Numbers are averaged over the years 2005 and 2006. Annual income per student in US Dollar calculated using an exchange rate of 140 Malawi Kwacha per US Dollar. Educated teachers are those teachers with a degree beyond the MSCE. Significance levels provided for $\mathrm{H} 0: \mu\left(\right.$ Community) $-\mu($ Conventional $)=0,{ }^{* * *} \mathrm{p}<0.01,{ }^{* *} \mathrm{p}<0.05,{ }^{*} \mathrm{p}<0.1$. 
Table 2: School size, physical resources, and human resources in day and boarding conventional schools

\begin{tabular}{|c|c|c|c|c|c|c|c|c|}
\hline & \multicolumn{3}{|c|}{$\begin{array}{l}\text { Conventional Day } \\
\text { Schools }\end{array}$} & \multicolumn{3}{|c|}{$\begin{array}{c}\text { Conventional Boarding } \\
\text { Schools }\end{array}$} & \multirow[b]{2}{*}{ T-Stat } & \multirow[b]{3}{*}{$*$} \\
\hline & $\mathbf{N}$ & Mean & SE & $\mathbf{N}$ & Mean & SE & & \\
\hline School size (number of pupils) & 49 & 409 & 37.1 & 64 & 499 & 36.2 & -1.75 & \\
\hline \multicolumn{9}{|l|}{ Income } \\
\hline Annual school fees per student in US Dollar & 49 & 18 & 14.3 & 64 & 100 & 69.5 & -1.16 & \\
\hline Annual school income per student in US Dollar & 49 & 68 & 29.2 & 64 & 230 & 110.0 & -1.42 & \\
\hline \multicolumn{9}{|l|}{ Human Resources } \\
\hline Teachers per 100 pupils & 49 & 4.5 & 0.2 & 64 & 4.3 & 0.1 & 0.83 & \\
\hline Educated teachers per 100 pupils & 49 & 4.0 & 0.2 & 64 & 4.0 & 0.1 & -0.14 & \\
\hline Non-teaching staff per 100 pupils & 44 & 2.0 & 0.2 & 57 & 3.0 & 0.2 & -3.41 & $* * *$ \\
\hline \multicolumn{9}{|l|}{ Physical Resources } \\
\hline Percentage of schools with a library & 49 & 82 & 5.6 & 64 & 94 & 3.0 & -1.90 & $*$ \\
\hline Percentage of schools with a PC room & 49 & 31 & 6.7 & 64 & 59 & 6.2 & -3.17 & $* * *$ \\
\hline Percentage of schools with toilets & 49 & 63 & 7.0 & 64 & 91 & 3.7 & -3.48 & $* * *$ \\
\hline Percentage of schools with water from tap or borehole & 49 & 90 & 3.9 & 64 & 88 & 3.1 & 0.31 & \\
\hline Percentage of schools with electricity & 49 & 74 & 5.9 & 64 & 88 & 3.3 & -1.93 & * \\
\hline Classrooms per 100 pupils & 49 & 2.73 & 0.20 & 64 & 2.08 & 0.09 & 2.90 & $* * *$ \\
\hline Book to pupil ratio (chichewa) & 44 & 1.26 & 0.23 & 57 & 0.49 & 0.07 & 3.29 & $* * *$ \\
\hline Book to pupil ratio (English) & 44 & 1.54 & 0.26 & 57 & 0.78 & 0.11 & 2.63 & $* *$ \\
\hline Book to pupil ratio (mathematics) & 44 & 1.36 & 0.24 & 57 & 0.86 & 0.17 & 1.77 & * \\
\hline
\end{tabular}

Source: EMIS 2005 and EMIS 2006. Schools included are those for which the Ministry of Education selected the 2005 Form 1 pupils. Numbers are averaged over the years 2005 and 2006. Annual income per student in US Dollar calculated using an exchange rate of 140 Malawi Kwacha per US Dollar. Educated teachers are those teachers with a degree beyond the MSCE. Significance levels provided for $\mathrm{H} 0: \mu($ day $)-\mu($ boarding $)=0, * * * p<0.01, * * \mathrm{p}<0.05,{ }^{*} \mathrm{p}<0.1$. 
Table 3: Impact of selection into a conventional secondary school

\begin{tabular}{|c|c|c|c|c|c|c|c|c|}
\hline \multirow[t]{2}{*}{$\begin{array}{l}\text { Order of } \\
\text { Polynomial }\end{array}$} & \multicolumn{2}{|c|}{ Passing JCE } & \multicolumn{2}{|c|}{$\begin{array}{c}\text { Pupil } \\
\text { Retention }\end{array}$} & \multicolumn{2}{|c|}{ Pupil learning } & \multicolumn{2}{|c|}{$\begin{array}{c}\text { Pupil } \\
\text { Learning, } \\
\text { upper bound }\end{array}$} \\
\hline & & (1) & & (2) & (3 & & & (4) \\
\hline \multicolumn{9}{|l|}{ Male pupils } \\
\hline 1 st order & $\begin{array}{c}0.18 \\
(0.02)\end{array}$ & $* * *$ & $\begin{array}{c}0.25 \\
(0.02)\end{array}$ & $* * *$ AIC & $\begin{array}{l}-0.09 \\
(0.02)\end{array}$ & $* * *$ & $\begin{array}{c}0.31 \\
(0.02)\end{array}$ & $* * *$ \\
\hline 2nd order & $\begin{array}{c}0.27 \\
(0.03)\end{array}$ & $* * *$ AIC & $\begin{array}{c}0.28 \\
(0.03)\end{array}$ & $* * *$ & $\begin{array}{c}0.02 \\
(0.02)\end{array}$ & & $\begin{array}{c}0.42 \\
(0.02)\end{array}$ & *** AIC \\
\hline 3 rd order & $\begin{array}{c}0.27 \\
(0.03)\end{array}$ & $* * *$ & $\begin{array}{r}0.29 \\
(0.03)\end{array}$ & $* * *$ & $\begin{array}{c}0.02 \\
(0.02)\end{array}$ & AIC & $\begin{array}{c}0.46 \\
(0.03)\end{array}$ & $* * *$ \\
\hline Observations & 21131 & & 21131 & & 11654 & & 15359 & \\
\hline \multicolumn{9}{|l|}{ Female pupils } \\
\hline 1 st order & $\begin{array}{c}0.21 \\
(0.03)\end{array}$ & $* * *$ & $\begin{array}{c}0.28 \\
(0.03)\end{array}$ & *** AIC & $\begin{array}{l}-0.03 \\
(0.03)\end{array}$ & & $\begin{array}{c}0.44 \\
(0.03)\end{array}$ & $* * *$ \\
\hline 2nd order & $\begin{array}{c}0.26 \\
(0.03)\end{array}$ & $* * *$ & $\begin{array}{c}0.31 \\
(0.04)\end{array}$ & $* * *$ & $\begin{array}{c}0.04 \\
(0.04)\end{array}$ & & $\begin{array}{c}0.61 \\
(0.06)\end{array}$ & $* * *$ \\
\hline 3rd order & $\begin{array}{c}0.29 \\
(0.04)\end{array}$ & $* * *$ AIC & $\begin{array}{r}0.32 \\
(0.04)\end{array}$ & $* * *$ & $\begin{array}{c}0.04 \\
(0.04)\end{array}$ & AIC & $\begin{array}{c}0.78 \\
(0.10)\end{array}$ & *** AIC \\
\hline Observations & 17536 & & 17536 & & 8480 & & 12276 & \\
\hline
\end{tabular}

Source: MANEB and Ministry of Education selection data. Two-stage least squares estimates of the effect of selection into a conventional school on the fraction of pupils passing the JCE in 2006 in the school into which they were selected, on the fraction of pupils retained, and on pupil performance (i.e. the fraction of pupils of passing the JCE conditional on participating in the school they were selected into). Standard errors in parentheses are clustered by secondary school. AIC $=$ optimal order of polynomial in second stage regression according to the Akaike information criterion. Dummies for regression discontinuity groups were included in the estimation. ${ }^{* * *} \mathrm{p}<0.01,{ }^{* *} \mathrm{p}<0.05,{ }^{*} \mathrm{p}<0.1$. 
Table 4.

\begin{tabular}{|c|c|c|c|c|c|c|}
\hline \multicolumn{3}{|c|}{$\begin{array}{c}\text { Cutoff range } \\
\text { (Distance to mean } \\
\text { PSCLE in standard } \\
\text { deviations) }\end{array}$} & Observations & Retention & \multicolumn{2}{|l|}{ SE } \\
\hline \multicolumn{3}{|c|}{ (1) } & (2) & (3) & \multicolumn{2}{|l|}{ (4) } \\
\hline \multicolumn{7}{|c|}{ Male pupils } \\
\hline-2.14 & - & -0.04 & 2559 & 0.14 & 0.09 & $*$ \\
\hline 0.01 & - & 0.42 & 2563 & 0.27 & 0.06 & $* * *$ \\
\hline 0.52 & - & 0.73 & 2445 & 0.32 & 0.06 & $* * *$ \\
\hline 0.75 & - & 0.83 & 2445 & 0.13 & 0.15 & \\
\hline 0.85 & - & 0.91 & 2249 & 0.36 & 0.07 & $* * *$ \\
\hline 0.93 & - & 0.96 & 3411 & 0.25 & 0.07 & $* * *$ \\
\hline 1.01 & - & 1.11 & 2738 & 0.30 & 0.05 & $* * *$ \\
\hline 1.21 & - & 1.80 & 2721 & 0.16 & 0.06 & $* * *$ \\
\hline \multicolumn{7}{|c|}{ Female pupils } \\
\hline-1.92 & - & -0.09 & 2112 & 0.17 & 0.10 & $*$ \\
\hline-0.01 & - & 0.51 & 2232 & 0.26 & 0.09 & $* * *$ \\
\hline 0.61 & - & 0.72 & 2101 & 0.23 & 0.05 & $* * *$ \\
\hline 0.80 & - & 0.93 & 2084 & 0.36 & 0.08 & $* * *$ \\
\hline 0.95 & - & 1.06 & 1670 & 0.07 & 0.14 & \\
\hline 1.11 & - & 1.21 & 2413 & 0.31 & 0.09 & $* * *$ \\
\hline 1.24 & - & 1.35 & 2550 & 0.18 & 0.10 & $* *$ \\
\hline 1.40 & - & 1.92 & 2374 & 0.28 & 0.06 & $* * *$ \\
\hline
\end{tabular}

Source: MANEB and Ministry of Education selection data. Two-stage least squares estimates of the effect of selection into conventional school on pupil retention for 8 ranges of the PSLCE scores representing roughly $12.5 \%$ of the pupils taking the PSLCE each. Cutoff ranges are normalized vis-à-vis the aggregate PSLCE scores of pupils selected into public secondary schools. Regressions contain first order polynomial terms of difference between PSLCE score and cutoff. Standard errors are clustered by secondary school. Dummies for regression discontinuity groups were included in the estimation. ${ }^{* * *} \mathrm{p}<0.01,{ }^{* *} \mathrm{p}<0.05,{ }^{*} \mathrm{p}<0.1$. 
Table 5

\section{$\begin{array}{cc}\text { Order of Polynomial } & \text { Taking JCE in } \\ \text { Boarding Conventional }\end{array}$}

\begin{tabular}{lll}
$\begin{array}{ll}\text { Male pupils } \\
\text { 1st order }\end{array}$ & -0.10 & AIC \\
& $(0.11)$ & \\
2nd order & -0.54 & \\
& $(0.36)$ & \\
3rd order & -1.36 & \\
& $(1.03)$ & \\
Observations & 3,753 & AIC \\
Female pupils & & \\
1st order & -0.13 \\
& $(0.34)$ & \\
2nd order & 1.95 \\
& $(2.39)$ \\
3rd order & 0.64 \\
& $(0.67)$ \\
Observations & 3443 \\
\hline \hline
\end{tabular}

Source: MANEB and Ministry of Education selection data. Two-stage least squares estimates of the effect of selection into boarding conventional school vs day conventional school on the fraction of pupils retained. Standard errors in parentheses are clustered by secondary school. AIC $=$ optimal order of polynomial in second stage regression according to the Akaike information criterion. Dummies for regression discontinuity groups were included in the estimation. ${ }^{* * *}$ $\mathrm{p}<0.01,{ }^{* *} \mathrm{p}<0.05,{ }^{*} \mathrm{p}<0.1$. 
Table 6.

\begin{tabular}{|c|c|c|c|c|c|c|c|c|c|c|c|c|}
\hline \multirow[t]{2}{*}{ Order of Polynomial } & \multicolumn{2}{|c|}{ Pooled } & \multicolumn{2}{|c|}{ Northern Region } & \multicolumn{2}{|c|}{ Other Regions } & \multicolumn{2}{|c|}{ Urban } & \multicolumn{2}{|c|}{ Rural } & \multicolumn{2}{|c|}{ Correct Selection } \\
\hline & & (1) & & (2) & & (3) & & $(4)$ & & $(5)$ & & (6) \\
\hline \multicolumn{13}{|l|}{ Male pupils } \\
\hline 1st order & $\begin{array}{l}0.25 \\
(0.02)\end{array}$ & $* * * \mathrm{AIC}$ & $\begin{array}{l}0.26 \\
(0.08)\end{array}$ & $* * *$ & $\begin{array}{l}0.25 \\
(0.02)\end{array}$ & $* * *$ AIC & $\begin{array}{l}0.32 \\
(0.08)\end{array}$ & $* * * \dagger$ & $\begin{array}{l}0.24 \\
(0.02)\end{array}$ & $* * *$ AIC & $\begin{array}{l}0.24 \\
(0.02)\end{array}$ & $* * *$ \\
\hline 2nd order & $\begin{array}{l}0.28 \\
(0.03)\end{array}$ & $* * *$ & $\begin{array}{l}0.31 \\
(0.1)\end{array}$ & $* * *$ & $\begin{array}{l}0.28 \\
(0.03)\end{array}$ & $* * *$ & $\begin{array}{l}0.35 \\
(0.09)\end{array}$ & $* * * \dagger$ & $\begin{array}{l}0.28 \\
(0.03)\end{array}$ & $* * *$ & $\begin{array}{l}0.28 \\
(0.03)\end{array}$ & $* * * \mathrm{AIC}$ \\
\hline $3 r d$ order & $\begin{array}{l}0.29 \\
(0.03)\end{array}$ & $* * *$ & $\begin{array}{l}0.23 \\
(0.12)\end{array}$ & $* *$ AIC & $\begin{array}{l}0.29 \\
(0.03)\end{array}$ & $* * *$ & $\begin{array}{l}0.35 \\
(0.1)\end{array}$ & $* * *+\mathrm{AIC}$ & $\begin{array}{l}0.28 \\
(0.03)\end{array}$ & $* * *$ & $\begin{array}{l}0.27 \\
(0.03)\end{array}$ & $* * *$ \\
\hline Observations & 21131 & & 4316 & & 16815 & & 2121 & & 18703 & & 20678 & \\
\hline \multicolumn{13}{|l|}{ Female pupils } \\
\hline 1st order & $\begin{array}{l}0.28 \\
(0.03)\end{array}$ & $* * *$ AIC & $\begin{array}{l}0.21 \\
(0.08)\end{array}$ & $* * * \mathrm{AIC}$ & $\begin{array}{l}0.29 \\
(0.03)\end{array}$ & $* * *$ & $\begin{array}{l}0.39 \\
(0.08)\end{array}$ & $* * * \ddagger \mathrm{AIC}$ & $\begin{array}{l}0.23 \\
(0.03)\end{array}$ & $* * *$ AIC & $\begin{array}{l}0.28 \\
(0.03)\end{array}$ & $* * *$ \\
\hline 2nd order & $\begin{array}{l}0.31 \\
(0.04)\end{array}$ & $* * *$ & $\begin{array}{l}0.32 \\
(0.13)\end{array}$ & $* *$ & $\begin{array}{l}0.31 \\
(0.03)\end{array}$ & $* * * \mathrm{AIC}$ & $\begin{array}{l}0.45 \\
(0.08)\end{array}$ & $* * * \neq$ & $\begin{array}{l}0.29 \\
(0.04)\end{array}$ & $* * *$ & $\begin{array}{l}0.29 \\
(0.03)\end{array}$ & $* * * \mathrm{AIC}$ \\
\hline 3rd order & $\begin{array}{l}0.32 \\
(0.04)\end{array}$ & $* * *$ & $\begin{array}{l}0.39 \\
(0.23)\end{array}$ & $*$ & $\begin{array}{l}0.33 \\
(0.04)\end{array}$ & $* * *$ & $\begin{array}{l}0.46 \\
(0.09)\end{array}$ & $* * * \ddagger$ & $\begin{array}{l}0.29 \\
(0.04)\end{array}$ & $* * *$ & $\begin{array}{l}0.29 \\
(0.04)\end{array}$ & $* * *$ \\
\hline Observations & 17536 & & 3686 & & 13850 & & 2339 & & 14947 & & 16877 & \\
\hline
\end{tabular}

Source: MANEB and Ministry of Education selection data. Two-stage least squares estimates of the effect of selection into conventional school on the fraction of pupils retained (in the school they were selected into). Standard errors in parentheses are clustered by secondary school. AIC $=$ optimal order of polynomial in second stage regression according to the Akaike information criterion. Dummies for regresion discontinuity groups were included in the estimation. $* * * \mathrm{p}<0.01, * * \mathrm{p}<0.05, *$ $\mathrm{p}<0.1 . \ddagger$ Estimate differs from pooled estimate at $\mathrm{p}<0.01$ based on Chow forecast test, $\dagger$ estimate differs at $\mathrm{p}<0.05$. 


\section{Figures}

Figure 1a: Fraction of boys selected to enter Form1 in a conventional school in 2005 as a function of the difference between their 2004 PSLCE score and the 2004 conventional school cutoff score.

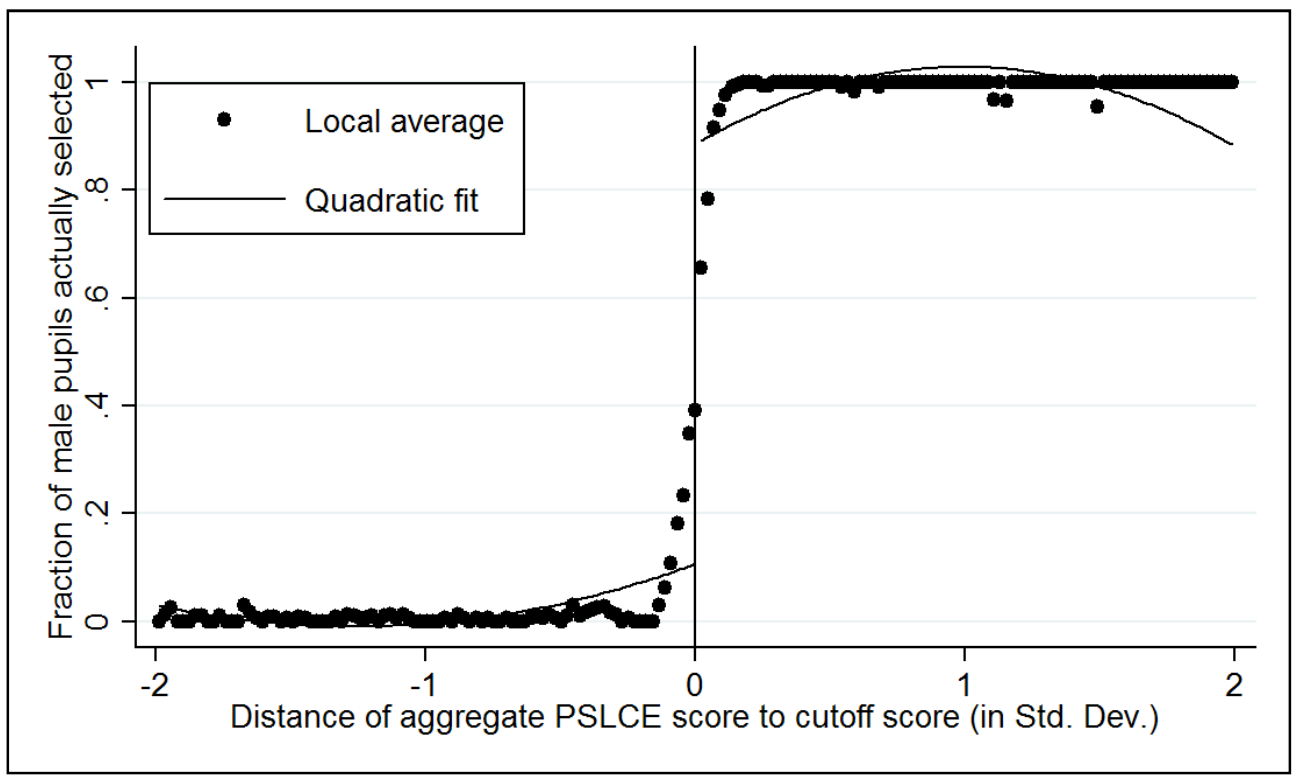

Figure 1b: Fraction of girls selected to enter Form1 in a conventional school in 2005 as a function of the difference between their 2004 PSLCE score and the 2004 conventional school cutoff score.

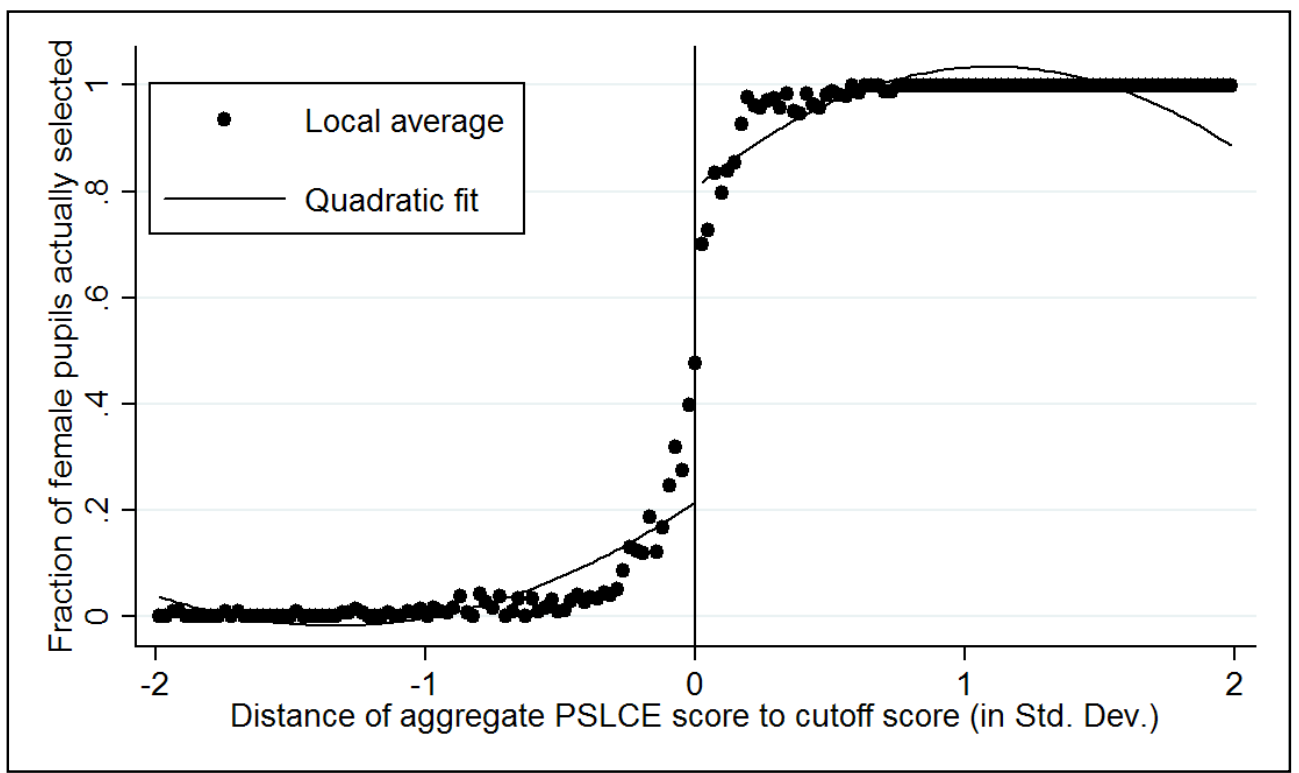


Figure 2a: Fraction of boys passing the JCE in 2006 in the school they had been selected into as a function of the difference between their 2004 PSLCE score and the 2004 cutoff score.

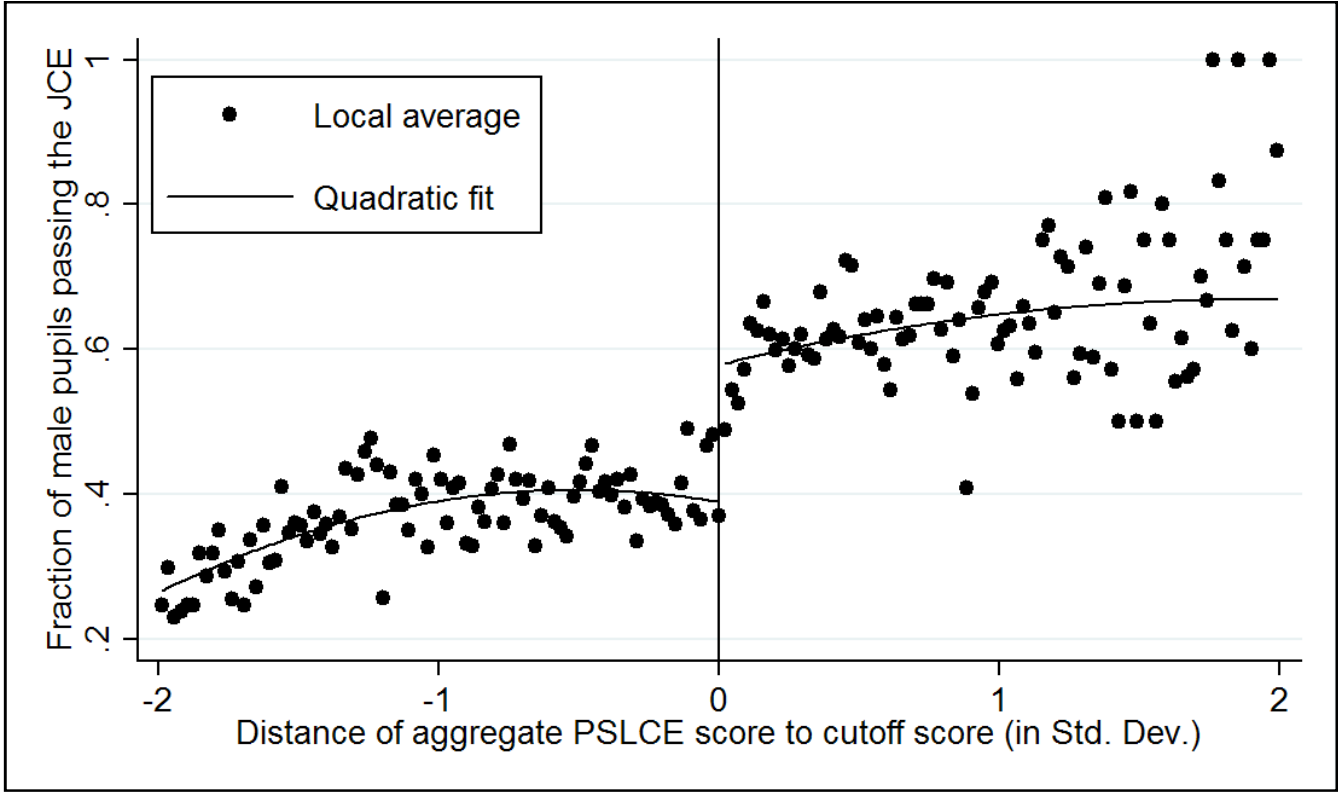

Figure 2b: Fraction of girls passing the JCE in 2006 in the school they had been selected into as a function of the difference between their 2004 PSLCE score and the 2004 cutoff score.

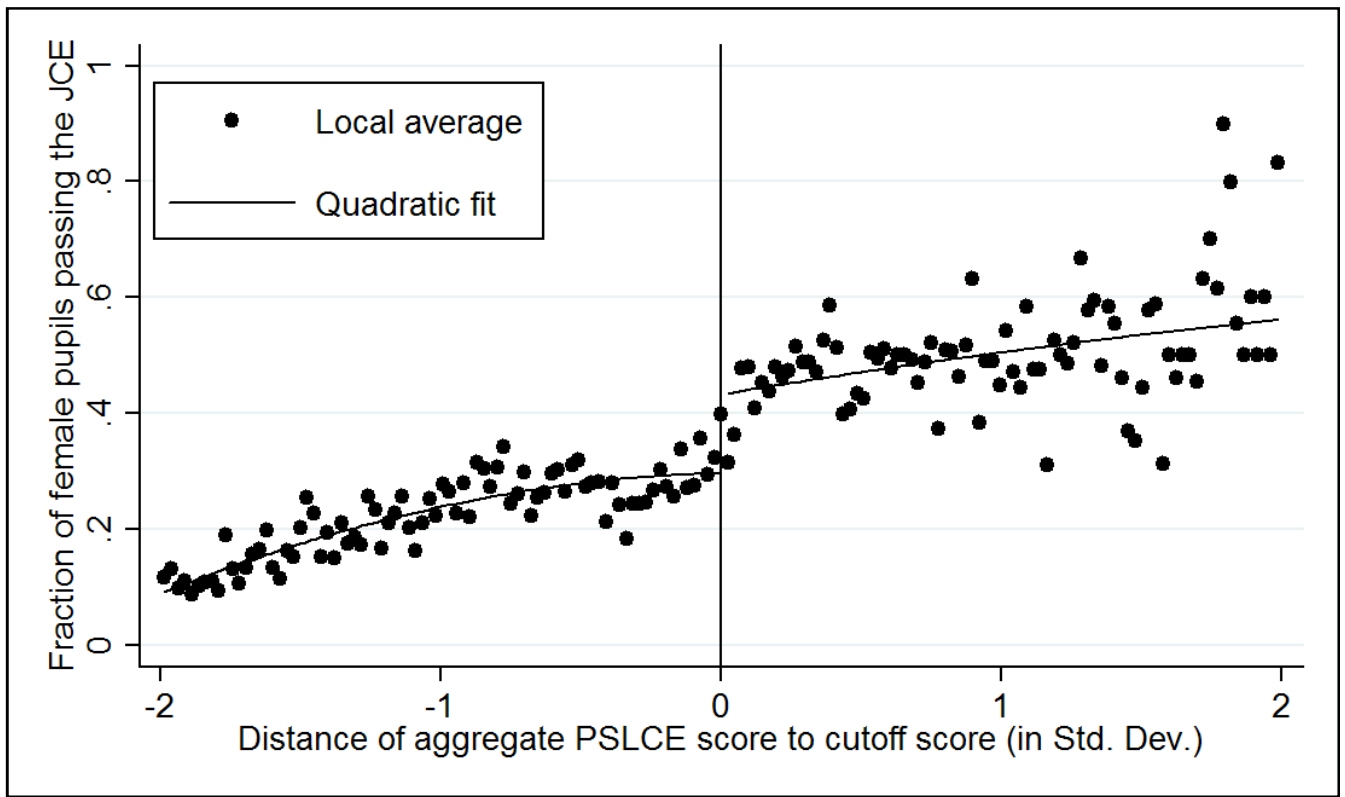


Figure 3a: Fraction of boys retained as a function of the difference between their 2004 PSLCE score and the 2004 cutoff score.

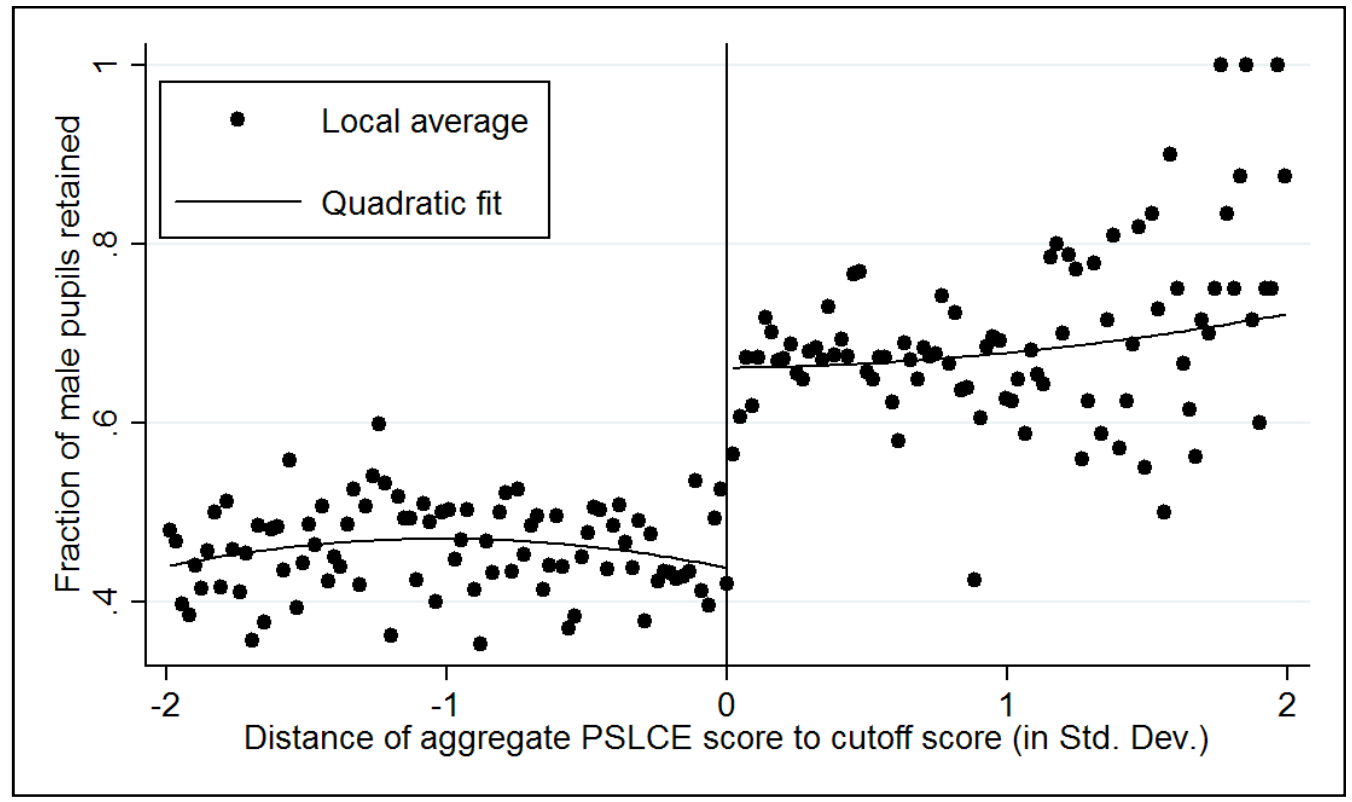

Figure 3b: Fraction of girls retained as a function of the difference between their 2004 PSLCE score and the 2004 cutoff score.

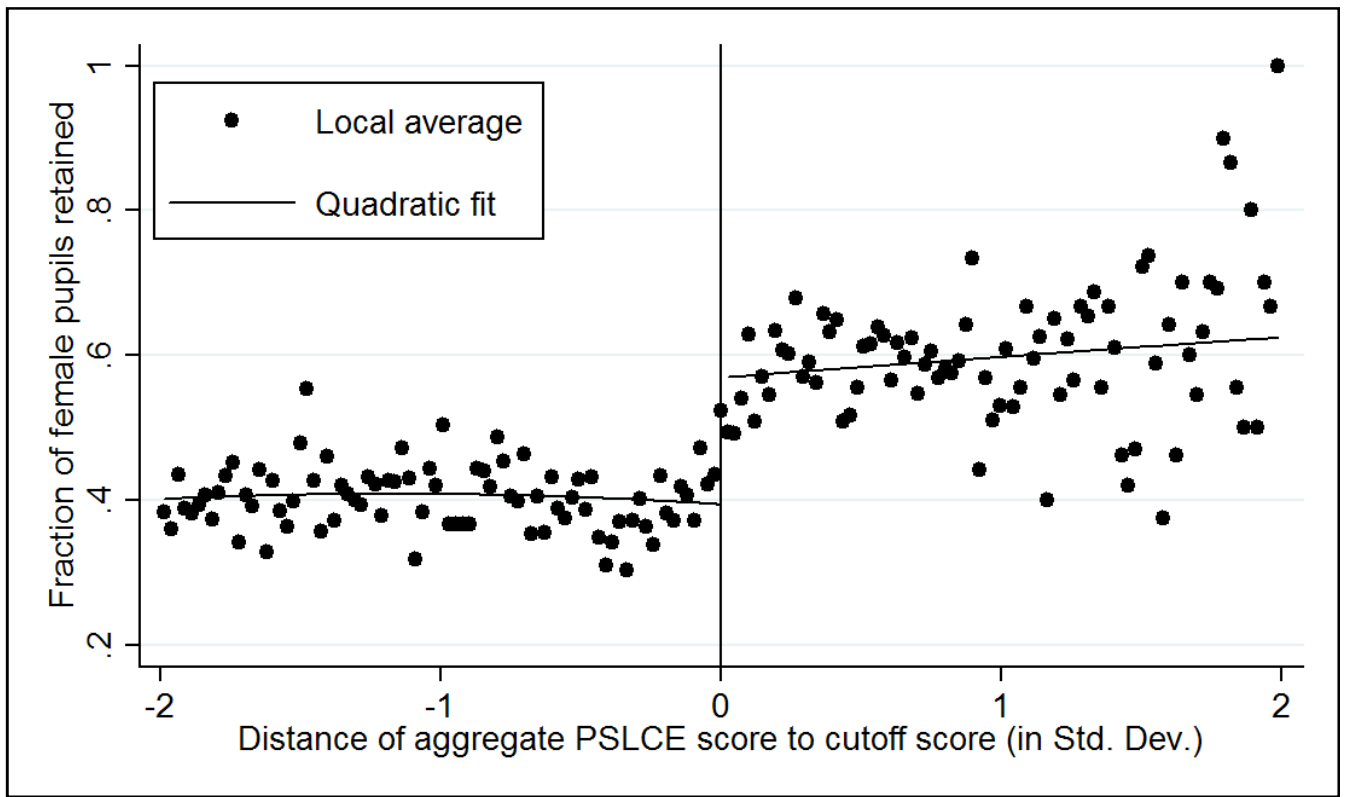


Figure 4b: Fraction of boys passing the JCE in 2006 conditional on actually taking the JCE in 2006 in the school they had been selected into as a function of the difference between their 2004 PSLCE score and the 2004 cutoff score.

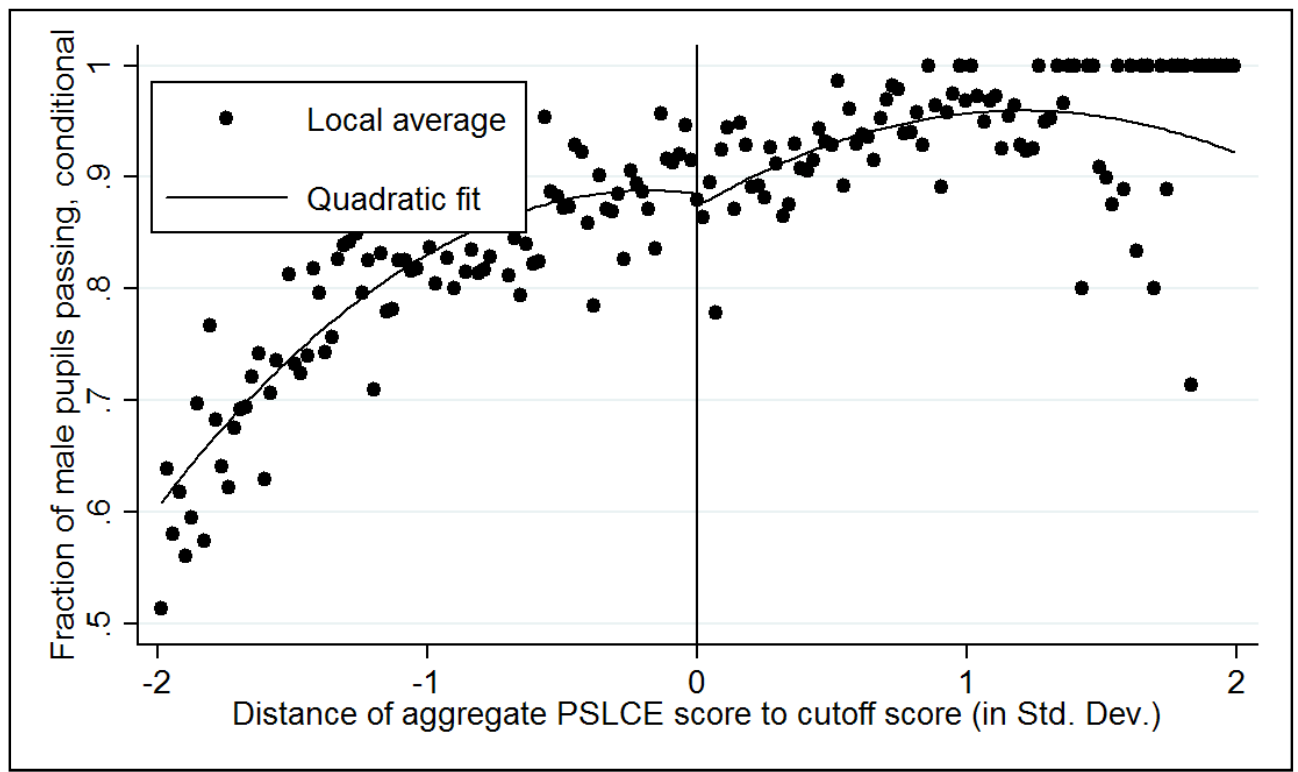

Figure 4b: Fraction of girls passing the JCE in 2006 conditional on actually taking the JCE in 2006 in the school they had been selected into as a function of the difference between their 2004 PSLCE score and the 2004 cutoff score.

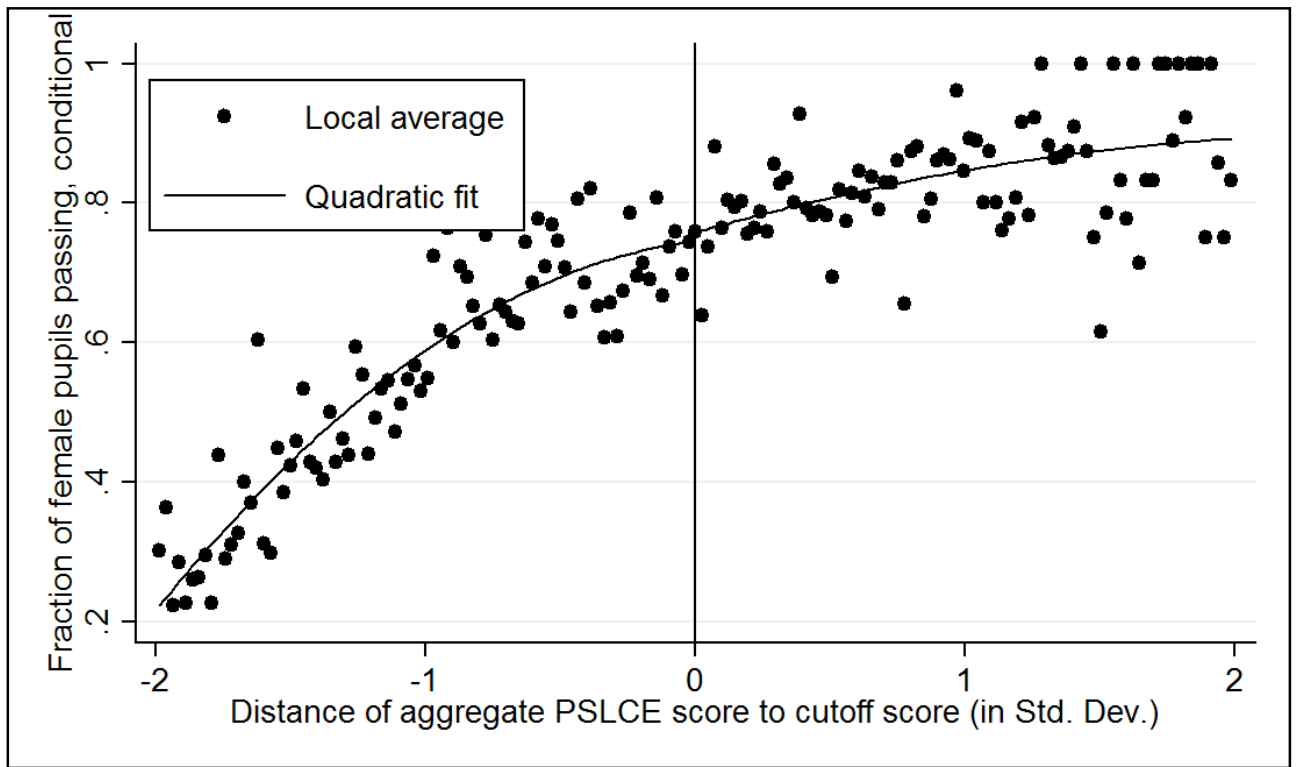


Figure 5a: Density of the difference between the 2004 PSLCE score of male pupils and the 2004 conventional school cutoff score.

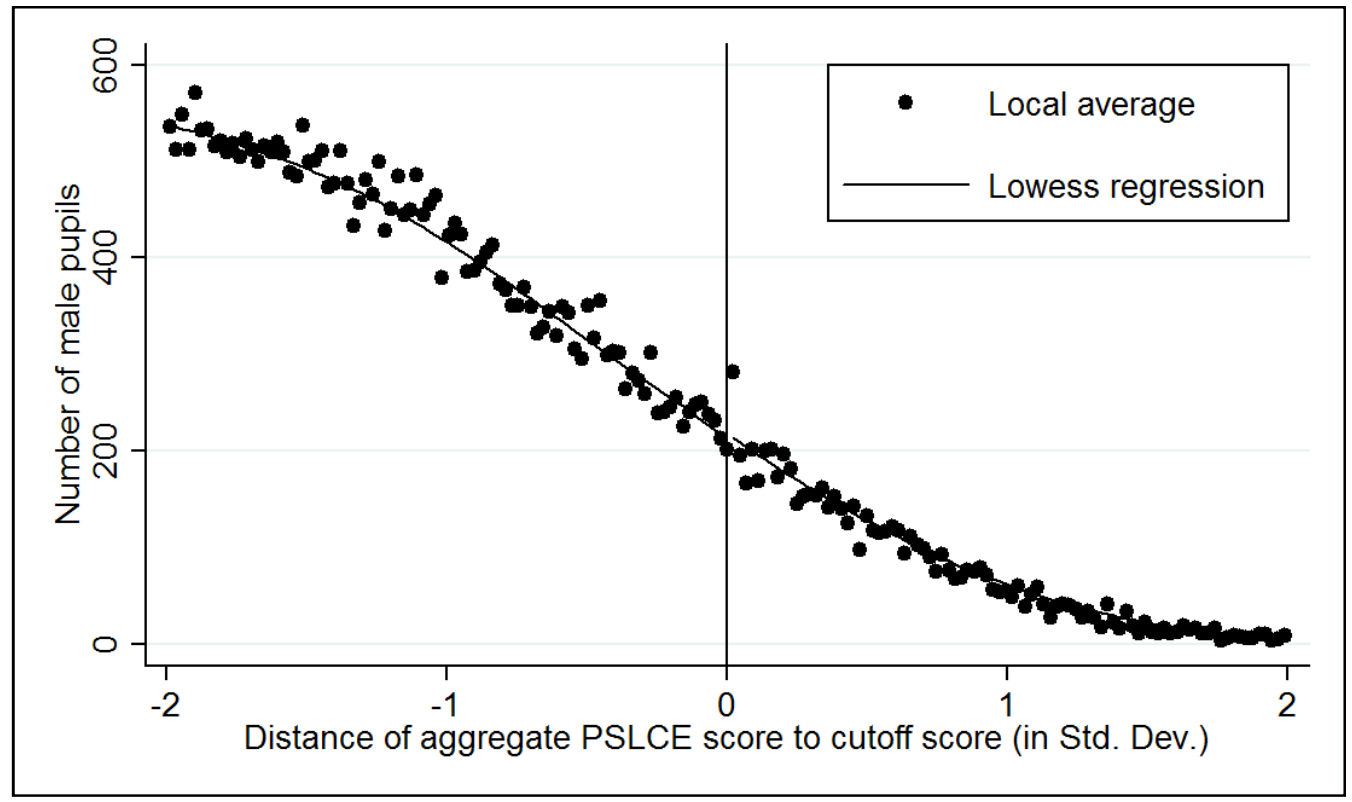

Figure 5b: Density of the difference between the 2004 PSLCE score of female pupils and the 2004 conventional school cutoff score.

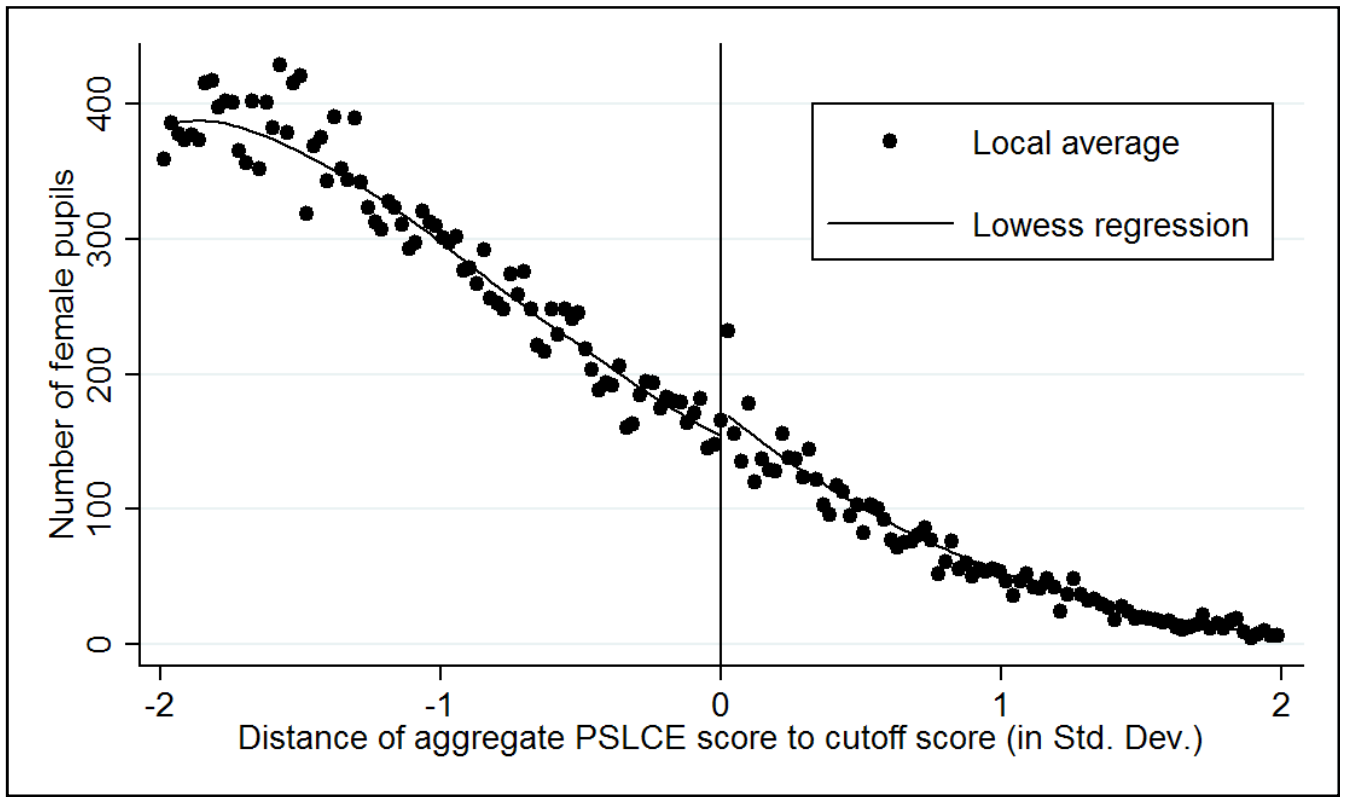

